\title{
Rehabilitation Strategies after Spinal Cord Injury: Inquiry into the Mechanisms of Success and Failure
}

\author{
Marie-Pascale Côté, Marion Murray, and Michel A. Lemay²
}

\begin{abstract}
Body-weight supported locomotor training (BWST) promotes recovery of load-bearing stepping in lower mammals, but its efficacy in individuals with a spinal cord injury (SCI) is limited and highly dependent on injury severity. While animal models with complete spinal transections recover stepping with step-training, motor complete SCI individuals do not, despite similarly intensive training. In this review, we examine the significant differences between humans and animal models that may explain this discrepancy in the results obtained with BWST. We also summarize the known effects of SCI and locomotor training on the muscular, motoneuronal, interneuronal, and supraspinal systems in human and non-human models of SCI and address the potential causes for failure to translate to the clinic. The evidence points to a deficiency in neuronal activation as the mechanism of failure, rather than muscular insufficiency. While motoneuronal and interneuronal systems cannot be directly probed in humans, the changes brought upon by step-training in SCI animal models suggest a beneficial re-organization of the systems' responsiveness to descending and afferent feedback that support locomotor recovery. The literature on partial lesions in humans and animal models clearly demonstrate a greater dependency on supraspinal input to the lumbar cord in humans than in non-human mammals for locomotion. Recent results with epidural stimulation that activates the lumbar interneuronal networks and/or increases the overall excitability of the locomotor centers suggest that these centers are much more dependent on the supraspinal tonic drive in humans. Sensory feedback shapes the locomotor output in animal models but does not appear to be sufficient to drive it in humans.
\end{abstract}

Keywords: locomotor function; neuroplasticity; rehabilitation; spinal cord injury

\section{Introduction}

C ONSIDERABLE PROGRESS HAS BEEN MADE in the last few years in understanding the effects of spinal cord injury (SCI) on function and in developing treatments to ameliorate deficits. Although several promising therapies have reached the clinical trial stage, outcomes (e.g., early termination due to significant side effects and lower than anticipated recovery of motor function) often fall short of our expectations. Most of the tested strategies aimed at improving functional recovery in SCI individuals were pharmacological in nature (e.g., drugs or secreting cell transplants), which may have serious systemic effects that prevent meeting quality-of-life standards. Among the factors responsible for the failure to successfully translate therapies to the clinic, two are of main concern: 1) the lack of knowledge about human SCI to compare with animal data, and 2) the divergence between strictly standardized and reproducible animal models of SCI versus the heterogeneity of human injuries. Both play a significant role when comparing the locomotor recovery obtained with activity-based therapies in animals and individuals, and interfere with the interpretation of outcomes.

\section{Locomotor recovery: successes from the bench to the bedside}

Non-invasive interventions, including various types of motor training (e.g., ladder walking, reaching, bicycling, swimming, and locomotor training on a treadmill) decrease the inflammatory response, increase neurotrophin levels, and may strengthen spared functions and guide spinal reorganization. Locomotor training successfully improves the recovery of stepping movements in various animal models including mice, ${ }^{1,2}$ rats,,${ }^{3,4}$ and cats (Fig. 1).$^{5-10}$ There is evidence that anatomical and physiological changes promoted by training in spinal animals occur both within ${ }^{11,12}$ and outside the locomotor circuitry, ${ }^{13-15}$ although the mechanisms are unclear.

Some success also has been achieved in SCI individuals (Fig. 1) ${ }^{16-18}$ Motor incomplete SCI individuals (i.e., C or D on the American Spinal Injury Association Impairment Scale [AIS]) ${ }^{19-22}$ show some improvements in overground locomotion, as measured by a reduction in the requirement for body weight support and the return of some independent stepping. In motor complete SCI individuals (AIS A and AIS B), several aspects of the locomotor

\footnotetext{
${ }^{1}$ Department of Neurobiology and Anatomy, Drexel University College of Medicine, Philadelphia, Pennsylvania.

${ }^{2}$ Department of Bioengineering, Temple University, Philadelphia, Pennsylvania.
} 


\section{LOCOMOTOR TRAINING INDUCED PLASTICITY}
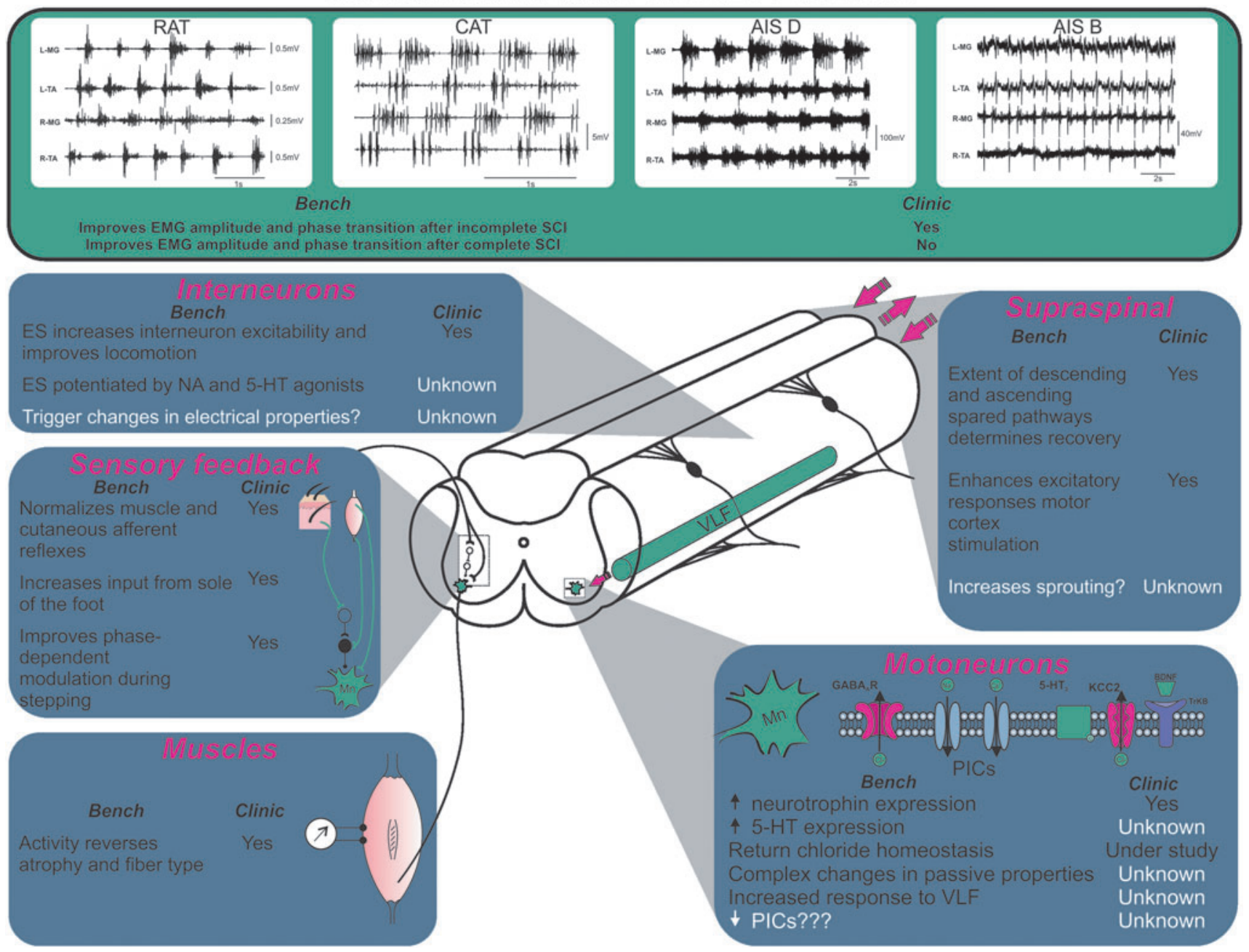

FIG. 1. Locomotor training induced plasticity in animals and humans. Summary of the effects of step-training on various aspects of the locomotor circuitry in animal models (all panels, left) and in humans (all panels, right). Electromyographic (EMG) data for complete and incomplete spinal cord injury (SCI) individuals provided courtesy of Dr. Maria Knikou. AIS, American Spinal Injury Association Impairment Scale; ES, electrical stimulation; NA, noradrenalin; VLF, ventrolateral funiculus; PICs, persistent inward currents.

electromyographic (EMG) pattern improve, including increased EMG amplitude, changes in EMG onset and offset, improved reciprocal activation between extensors and flexors, and better alternation between the left and right legs. ${ }^{23-25}$ Even if the improvement in EMG activity does not translate to better overground walking despite intensive treadmill training, this nonetheless indicates that the locomotor circuitry responsible for phase transition (stance to swing and vice versa) is functional and can be activated by afferent inputs provided by repetitive movements of the legs.

Conditioning the soleus H-reflex is another promising therapy that results in improvements in locomotion for rats, cats, non-human primates, and even humans. ${ }^{26,27}$ Although some changes occur within the spinal networks, evidence in rats suggests that upconditioning requires an incomplete injury with an intact corticospinal tract (CST) ${ }^{28}$ A combination of H-reflex operant conditioning and locomotor training demonstrated a possible transfer of plasticity acquired from non-locomotor training task to locomotion. ${ }^{29,30}$ This approach suggests that training a non-locomotor related task may actually translate into locomotor benefits when nonlocomotor training targets the control of the spinal excitability state.

\section{Limitations to successful translation}

Body-weight supported locomotor training (BWST) is characterized by repetitive movements involving major muscle groups. An advantage of this therapy is the ability to tailor the program to the individual's specific needs and its integration into a complete rehabilitation program. However, little is known about the physiological adaptations to various "dosages" (intensity, volume, duration) and timing (e.g., onset time post-SCI). As we move forward, more studies will have to focus on this critical information given that an early training onset can be detrimental ${ }^{31}$ or beneficial $^{32}$ and that locomotor ability depends on the amount of practice and the number of repetitions ${ }^{4}$ that can be achieved without reaching overtraining. This lack of information contributes to the limited success of BWST after SCI.

Treatments that improve function in animal models of SCI have shown little meaningful recovery in humans, especially in severely impaired individuals. The most effective approach in animal models is a combination of treatments directed at different aspects of the injury process, which include immune responses, neuroprotection, and activation of depressed systems. Outcome measures 
for pre-clinical studies show a range of improvements, including cellular and molecular changes, while outcomes for clinical treatments are largely behavioral. Our understanding of just how the molecular and cellular plasticity affect the system's physiology, and subsequently the behavior, is limited in animals and even more so in humans. As long as this information remains unavailable, it will be challenging to evaluate the chance for a successful translation to SCI individuals.

It is difficult or, at present, impossible to assess and compare the effects of invasive treatments on the spinal cord structure and physiology in SCI patients with those shown in animal models. Invasive treatments are used only in adults with chronic severe (complete) injuries, who are the least likely to experience adverse effects but are also least likely to show recovery. Nevertheless, combination treatments, including locomotor training, identified from animal studies have been used in chronically injured motor complete individuals, although in small numbers. These have been shown to be safe and to provide some limited recovery. Similar treatments following incomplete injury have shown more functional recovery (Table 1$)$.

\section{Are Animal Models Still Valuable?}

There are similarities in the organization of the spinal cord among mammals. The central pattern generator (CPG) for locomotion is present in all vertebrates, including humans. The general features of its output are similar in rats, cats, and humans as evidenced by the flexion-extension rhythm evoked by non-patterned brainstem/spinal stimulation in all these species. ${ }^{33-35}$ The potential for greater complexity of the CPG in humans may, however, lead to an increased difficulty in identifying the effects of SCI and treatments. There also are similarities in the responses to interventions. Locomotor responses to epidural stimulation of the spinal circuits share similarities in rats, cats, and humans. ${ }^{36,37}$ Operant conditioning of the H-reflex ${ }^{26,27}$ or pharmacologic stimulation also can improve locomotion and diminish spasticity in rats, ${ }^{38-41}$ cats, ${ }^{42,43}$ and humans. ${ }^{44,45}$ Sprouting patterns after dorsal column lesion also are generally similar among animal models, and may contribute to recovery of sensory function in rats, primates, and humans. ${ }^{46,47}$ While dorsal root injury elicits sprouting of central pathways in rodents and cats, it surprisingly appears to be far more robust in non-human primates. ${ }^{48-51}$

However, there are significant differences across species that likely contribute to failure of translation. Rodents have smaller bodies, smaller brains, smaller descending tracts, and presumably fewer spinal interneurons and less sophisticated circuitry than large mammals. Despite the smaller size of the central nervous system (CNS) in rodents, their spinal cord accounts for $30 \%$ of the CNS net weight, while it only accounts for $3 \%$ in humans. ${ }^{52}$ Overall, the spinal cord in rodents may actually have proportionally more computing power than in humans. Mice show spontaneous recovery after transection, ${ }^{53}$ whereas rats require training and other treatments, although locomotion can be elicited by non-invasive strategies (i.e., training and perineal stimulation). ${ }^{54,55}$

Cats have provided important understanding of the CPG. Unlike humans, they show recovery of weight-support and locomotion after a complete spinal cord transection with single treatments such as step-training on the treadmill or delivery of neurotrophins. $5,6,56$ Cats are no longer used widely but perhaps they should be, considering the wealth of information about their spinal circuit organization, and could give clearer insight into the failure of translation in primates. Mini-pigs have also recently emerged as a promising new large animal model that may represent a useful intermediary between rodents and humans, especially for testing cell transplantation and regenerative strategies. ${ }^{57}$ Unfortunately, rehabilitation strategies involving BWST have not been tested so far in this model.

Monkeys and humans show greater recovery of locomotion and hand function than rats after a hemisection injury, and the extent of recovery is correlated with the formation of corticospinal detours that develop in monkeys but not in rats. ${ }^{58}$ The rat CST is located in the dorsal columns, with some CST axons descending in the ventral and lateral funiculi, whereas it is mostly found in the lateral funiculus in large animals, with some axons descending in the lateral and ventral funiculi. In addition to this differential location, the greater CST complexity in primates and humans versus rodents is evidenced by the increased abundance of bilateral projections, the joint participation of the motor and sensory cortices to the CST, a larger target spinal interneuronal pool, ${ }^{58}$ and the presence of direct monosynaptic projections to motoneurons. In addition, the CST innervating the spinal cord has at least nine different cortical origins in primates and humans, with a unique spinal termination pattern for each cortical region, whereas it mostly originates from the primary and somatosensory cortices in rodents. Given that the response to injury depends on the cortical origin, the potential for complexity is far greater. ${ }^{59}$ Together, these factors likely contribute to the failure of translation.

Relatively few studies directly compare species differences, and this limits interpreting translatable data from animal models. For example, an intervention that improves locomotor performance in rats by increasing appropriate sensory feedback may not be as successful in SCI individuals who appear to be much more dependent on supraspinal input to the cord (see sections below). Conversely, targeting an increase in supraspinal control of the locomotor centers may improve stepping more significantly in SCI individuals and show only minimal improvements in rats. Inconsistencies in results obtained in different animal models and primates/humans suggest that it might actually be more beneficial to conduct studies directly in humans for non-invasive interventions. Nevertheless, animal models remain valuable in understanding the mechanisms for recovery and failure and testing the safety of invasive treatments.

\section{Injury Severity: Are Animal Models Comparable to Humans?}

Complete injury results in the loss of supraspinal input, sprouting by interneurons, dorsal roots, and propriospinal neurons, with substantial changes in spinal circuits. A true complete transection of the spinal cord is uncommon in SCI individuals (14.3\%), ${ }^{60}$ and the majority of AIS A cases (clinically classified as motor and sensory complete) have a discomplete injury with some fibers surviving as illustrated by the rudimentary control of EMG responses below the lesion site. ${ }^{61}$ Treatments that increase excitability of spinal circuits in transected animals elicit robust recovery of locomotor function. These treatments usually include combinations of neurotrophins, grafts, pharmacotherapy, brain-machine interface, epidural stimulation, and intensive activity-based therapy, all of which may contribute to improved function. Both spinal cats and rats can achieve locomotion with either step-training or administration of neurotrophins. ${ }^{56,62}$ Such a successful recovery is not observed in motor complete SCI individuals with single treatments (Fig. 1).

Incomplete lesions include individuals with AIS B, C, and D. Asymmetric injury (i.e., hemisection) produces asymmetric impairment and spared contralateral projections can partially compensate for the ipsilateral loss. The greater spontaneous recovery in 


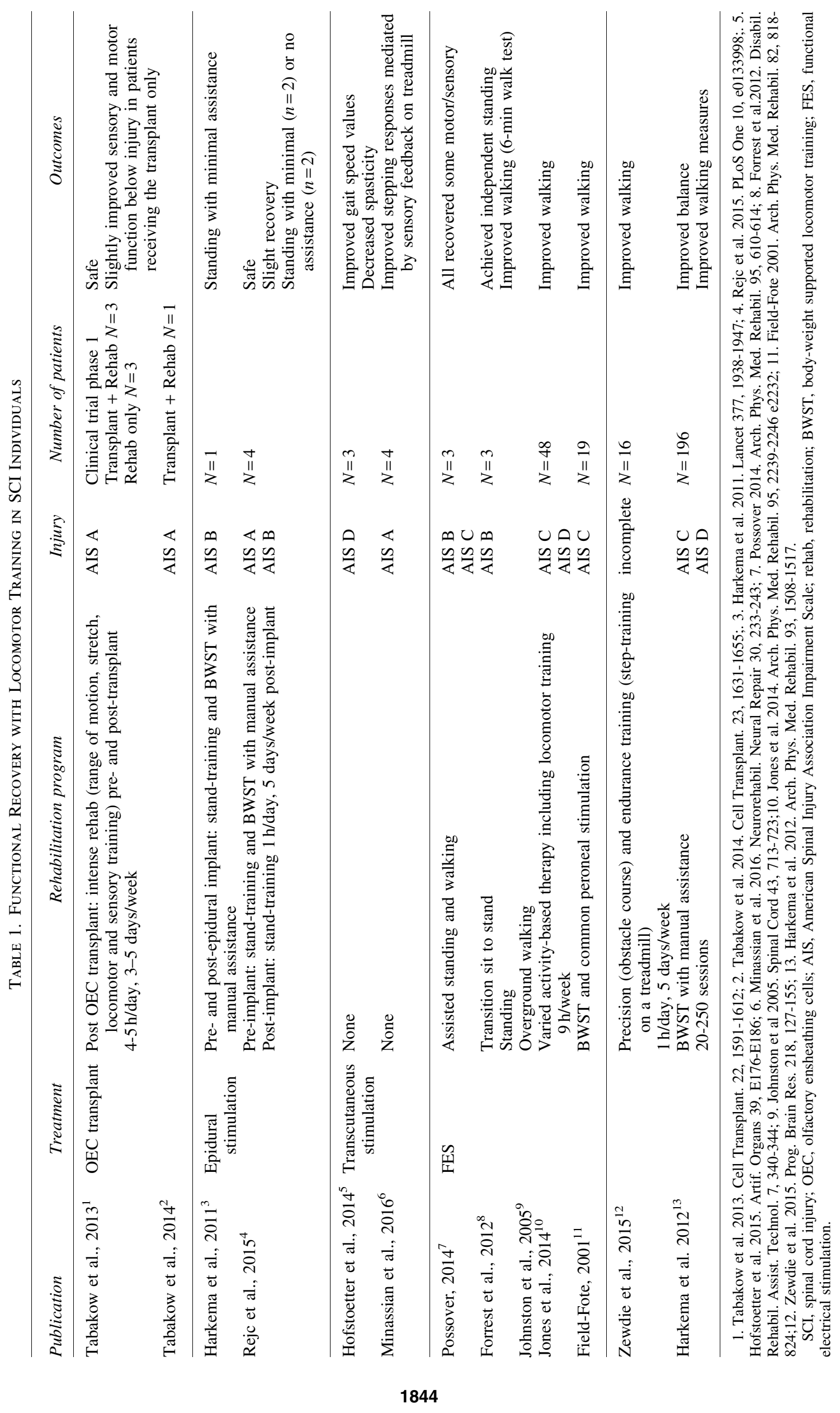


humans and primates ${ }^{58}$ is related to supraspinal pathways that project bilaterally and rely on spared pathways to support recovery. Consequently, the extent of laterality predicts the extent of recovery after incomplete SCI. ${ }^{63}$ Recovery of walking after incomplete lesions is critically dependent on descending input from the motor cortex and the ability to strengthen corticospinal connections. ${ }^{64}$ Spared descending axons rescue propriospinal plasticity, ${ }^{65}$ but propriospinal interneurons in primates appear to be more dependent on descending input than in rodents. ${ }^{66}$ It is difficult to assess whether there is a relative difference in the number or type of propriospinal interneurons in small versus large animals ${ }^{67}$ and how it may contribute to this effect. Another confounding factor may be the homogeneity of lesions in animal studies. Treatments successful in a given model of SCI in animals may poorly translate in clinical trials that include individuals with widely different injuries (cause and severity). Testing in various models of injury is critical to circumvent this problem.

\section{Changes in Skeletal Muscles Triggered by $\mathrm{SCl}$ Do Not Account for Failure}

Spinal cord injury and the ensuing muscular disuse lead to muscle atrophy for the muscles innervated by the motor pools below the lesion and conversion of these muscles' fiber type to fastfatigable glycogenic Type IIb. Atrophy occurs quickly with a 33$45 \%$ decline in muscle cross-sectional area 6 weeks following the injury. ${ }^{68,69}$ This rapid atrophy is accompanied by a slower conversion of type I muscle fibers to type IIb in both humans and animal models of SCI. ${ }^{70-75}$ The two phenomena combined produce a loss in muscle output for hind limb muscles in SCI individuals. Electrical stimulation can reverse the muscle mass loss and to some extent reverse the conversion of muscle fibers to a different type (Fig. 1), although the amount of conversion and gain in muscle force output varies depending on the stimulation protocol and the loading presented to the muscles being stimulated. ${ }^{72,73,76,77}$ The increased muscle activation brought on by spasticity may have effects similar to electrical stimulation. Spasticity can protect against muscle atrophy in SCI individuals ${ }^{78}$ but its effects on fiber types appear to be mixed. ${ }^{79}$

\section{Potential contribution of reduced force output to the failure of locomotor training program}

Studies in spinal cats show that the force-generating capacity of hind limb muscles is similar whether they received stand-training or not; all the trained animals could stand but stand-trained animals stand for longer periods. ${ }^{80,81}$ Stand-trained animals, however, show limited locomotor capabilities, compared with the step-trained animals. This suggests that difference in activation rather than muscular capacity is responsible for the stepping performance. Further support for this idea comes from studies in rats transected as neonates. There is less than a $10 \%$ difference in muscle mass (normalized to body mass) between animals able to weight-support versus non-weight-supporting animals as adults. ${ }^{82}$ The gain in muscle cross-sectional area following BWST also appears to be minimal in chronic incomplete SCI individuals (on the order of 5$10 \%),{ }^{83,84}$ although trained individuals show greater recovery with BWST. Overall, both animal and human experiments suggest that muscular atrophy and loss of joint torque following SCI are not major contributors to the failure of BWST training at restoring locomotor activity in complete SCI.

The muscular system output after SCI should therefore be sufficient to produce a locomotor pattern if fed an appropriate muscle activation sequence. The failure of BWST in humans seems to be more related to a failure in the spinal locomotor centers being either more depressed and/or more dependent on descending systems.

\section{Evidence in favor of the locomotor centers being depressed}

Recent successes in producing a locomotor pattern in motor complete SCI individuals, using a combination of BWST and epidural stimulation to increase the excitability of the spinal cord circuits, suggest that the inability to activate the locomotor centers may contribute to the failure of the use of BWST alone in humans (Fig. 1). Activation failure may be occurring in a number of locations within the locomotor circuitry chain including motoneurons, interneurons, and reflex pathways from the limbs' sensory feedback. Time since injury also influences the excitability state of the locomotor circuitry, with sustainable locomotor output driven by sensory feedback being diminished in chronic complete SCI. ${ }^{85}$

\section{Motoneurons as a Target for Locomotor Training: A Balancing Act between Increased and Decreased Activity}

\section{Persistent inward currents (PICs) contribute to increased excitability after $\mathrm{SCl}$}

The intrinsic properties of motoneurons are significantly influenced by neuromodulatory inputs that alter the resting potential, reduce the spike voltage threshold, and transform the input-output processing through the activation of voltage-gated PICs. ${ }^{86-90}$ PICs are strongly facilitated by monoamines (5-HT and noradrenalin) that are released by brainstem-spinal pathways ${ }^{91,92}$ and even more so after a chronic SCI. ${ }^{93,94}$ SCI leads to an immediate and dramatic reduction of motoneuronal excitability. ${ }^{95}$ The lack of neuromodulation prevents motoneurons from producing a firing frequency sufficient to generate muscle activation and production of enough force to sustain locomotion. After the spinal shock period during which no amount of synaptic activity can bring motoneurons to firing threshold, motoneuronal excitability gradually increases.

In the chronic state, the emergence of constitutive activity of the 5- $\mathrm{HT}_{2 \mathrm{C}}$ receptors leads to $\mathrm{Ca}^{2+}$ PICs recovery with the presence of plateau potentials that prolong and amplify inputs to motoneurons leading to excessive activity associated with muscle spasms in rodents. ${ }^{96-98}$ These studies were conducted in rats with a sacral SCI that have been used as a model that reproduces the clinical development of spasticity in humans. ${ }^{99}$ Although this model does not allow the investigation of the spinal control of limb movement but rather the activity of sacral motoneurons and tail musculature, studies in SCI individuals support the presence of a similar phenomenon in limb motoneurons. ${ }^{100,101}$ In addition, although PICs are recovered following SCI in cats, the movement-related receptive fields (MRRF) are no longer joint-specific: ankle extensor motoneurons are not only activated by passive ankle rotations but also by rotations of the hip. ${ }^{102,103}$ The injury-related widening of the MRRF is most likely due to the loss of monoaminergic modulation causing a disinhibition of polysynaptic excitatory pathways on target motoneurons, which has the potential to activate muscles through the entire limb and possibly contribute to spasms. ${ }^{102}$ It also is important to note that although a complete spinal cord transection typically is not considered the most clinically relevant model, these animals display more spasticity than contused animals, ${ }^{104}$ unlike SCI individuals who show more spasticity with moderate injuries. Therefore, 
successful translation may not always rely on matching the type/ extent of injury but rather on mimicking the clinical profile.

$\mathrm{Na}^{+}$PICs $\left(\mathrm{I}_{\mathrm{NaP}}\right)$ also are a key conductance for the locomotor networks as they can drive plateau potentials in motoneurons ${ }^{105}$ and contribute to repetitive firing and motoneuron hyperexcitability after chronic SCI. ${ }^{93}$ A recent study suggests that the upregulation of $\mathrm{I}_{\mathrm{NaP}}$ after SCI contributes to the development of spasticity through a cleavage of the Nav1.6 channel. ${ }^{106}$ SCI increases the expression of Nav1.6 channels in the lumbar spinal cord ${ }^{107}$ and preliminary results suggest that exercise could decrease the expression of $\beta_{1}$ and $\beta_{4}$ subunits. ${ }^{108}$ This pathway has recently been proposed to interact in synergy with the disruption in chloride homeostasis and lead to spasticity after chronic SCI. ${ }^{106}$

\section{Passive motoneuronal properties contribute to reduced excitability after $\mathrm{SCI}$}

Beyond the development of PICs, little is known about the effect of SCI on electrical properties of motoneurons and even less after a rehabilitation program. Muscle disuse and reduced neuromuscular activity decrease motoneuronal excitability with an elevated rheobase, lower afterhyperpolarization (AHP) depth, depolarized spike threshold, and a positive shift in the frequency-current $(f-I)$ relationship. ${ }^{109,110}$ However, changes in motoneuronal properties based on AHP depth, rheobase, input resistance, and $f$-I relationship after chronic SCI remain controversial. Most reports suggest no change and if anything, a general decrease in motoneuronal excitability, ${ }^{111-116}$ while increased excitability also has been reported. ${ }^{117,118}$ The heterogeneity of results obtained after chronic SCI may arise from various factors, including the model utilized (rat vs. cat), the type of muscle innervated by a motoneuronal pool (fast vs. slow muscle), time post-injury, and inter-animal variability (spastic vs. non spastic). Such a high degree of variability impedes interpretations of data about the changes in motoneuronal properties following SCI, and their potential effects on locomotor capability.

Step-training modifies motoneuron excitability in response to limb loading and cutaneous stimulation in an afferent-motor pool specific manner (see the section "Afferent feedback and spinal reflexes contribute to locomotor recovery"). ${ }^{13,14}$ Studies conducted in rats that sustained a complete transection as neonates showed that step-training does not change the rheobase but rather decreases the AHP amplitude and increases monosynaptic excitatory postsynaptic potentials (EPSPs). ${ }^{119}$ The efficacy of step-training is also correlated with the amplitude of synaptic inputs to motoneurons in particular from axons descending in the ipsilateral ventrolateral funiculus (VLF). ${ }^{19,120}$ Further, locomotor activity in spinal cats can be initiated by the activation of reticulospinal pathways that reside largely in the VLF. ${ }^{121}$ Further studies in rodents showed that the VLF also contains ascending and descending long propriospinal neurons (ispilateral and commissural) that interconnect the cervical and lumbar enlargements. ${ }^{122-124}$ Increased motoneuronal responses to VLF stimulation in step-trained animals after a complete SCI suggest an increased inter-enlargement connectivity that could participate in recovery. This interpretation is supported by clinical evidence in incomplete SCI individuals that show an improvement in the leg muscle activation upon engaging arm swing during gait. ${ }^{125,126}$

Overall, it remains unclear if direct modulation of motoneuronal properties contributes to motor recovery and/or failure for improvement (Fig. 1). Our current knowledge suggests a complex balance between decreased excitability (e.g., reduced response to specific afferent activation) and consequent decrease in hyperreflexia coupled to a facilitation in their response to descending pathways.
Whether these changes rely on plasticity in motoneuronal properties, increase/decrease in the number of synapses, or change in the strength of synapses to motoneurons needs further investigation.

\section{Changes in Interneuron Systems Involved in Locomotion}

Recent years have seen a breakthrough in interneuron identification supported by new genetic mouse models that provide increased specificity and the possibility to assess their roles and the identification of circuits. A number of ventral interneurons have been identified using transcription factors and shown to be either critical elements of the CPG or involved in locomotor pattern formation/shaping. ${ }^{127-129}$

\section{Interneurons controlling locomotion}

Interneurons play a significant role in the control of locomotion and are the main termination control and distribution sites for descending tracts and propriospinal systems. ${ }^{130,131}$ The expression of the locomotor pattern is facilitated by the intrinsic electrophysiological properties of interneurons. For example, PICs in interneurons can be triggered to amplify synaptic inputs and the consequent sustained firing is thought to be involved in rhythmogenesis by setting the timing and shaping the motor output during locomotion. ${ }^{132}$ Although the concept of a CPG for locomotion is generally accepted in both animals and humans, ${ }^{33,133}$ its interneuronal composition is only partly described and little is known about the effects of SCI and step-training on spinal interneurons, particularly in primates. ${ }^{134}$

Recent electrophysiological data support the concept that trainingdependent plasticity does indeed occur within the CPG,${ }^{135-137}$ as well as in reflex pathways ${ }^{13,14}$ and muscle spindles. ${ }^{15}$ The specific nature of the changes in CPG interneurons is unknown and warrants further investigation in both animals and humans (Fig. 1). Few studies have focused on direct changes in intrinsic properties of spinal interneurons with step-training after SCI. To our knowledge, the only available reports are in a mouse hemisection model that suggest that steptraining selectively increases the efficacy of synaptic connections from residual descending pathways to interneurons located in the vicinity of the lesion. ${ }^{138,139}$ There was relatively little change in the intrinsic properties of spinal interneurons (input resistance, rheobase current, threshold, action potential amplitude, afterhyperpolarization peak, etc.) between control and SCI mice whether they were steptrained or not. ${ }^{138-140}$ The data suggests that step-training favors plasticity of synaptic strength rather than intrinsic changes in properties of interneurons. However, it must be noted that this set of studies did not examine interneurons directly involved in locomotor output. The synaptic efficacy of descending systems, notably the CST, onto other interneurons caudal to the injury was enhanced with step-training as evidenced by the increased EPSP responses to deep dorsal column stimulation for deep dorsal horn interneurons caudal to the injury. ${ }^{139}$ It is again unclear if those interneurons are actually part of the locomotor circuitry.

The efficacy of other descending systems also appears to increase following SCI since a 100- to 1000-fold increase in serotonin sensitivity is observed in V2a interneurons responsible for left-right hind limb coordination in spinal animals. ${ }^{140}$ However, the specific effects of step-training on this hypersensitivity, which is not accompanied by changes in intrinsic properties, have not been explored. Although spinal interneurons become more responsive to descending inputs after SCI, the actual output of interneuronal systems may in fact be depressed. The cholinergic output of propriospinal neurons in lamina $\mathrm{X}$, those interneurons located around 
the central canal, onto motoneurons is significantly decreased after injury. ${ }^{141}$ These interneurons are believed to participate in locomotion $^{142,143}$ and receive extensive descending inputs from the mesencephalic locomotor region. ${ }^{142}$

An emerging hypothesis is that interneuronal systems in primates and humans may be more highly dependent on supraspinal tracts and that the loss of descending inputs may lead to a more severe impairment of the interneuronal systems that support the locomotor circuitry. Differences in the contributions of the interneuronal systems to locomotion and changes in those systems after injury and training have not been explored extensively, even in animal models of SCI, but may contribute to the differences in the recovery observed with training between humans and animal models of SCI.

\section{Propriospinal neurons contribute to novel relays after $\mathrm{SCl}$}

The extent of recovery is often associated with the amount of spared descending tracts. With that in mind, several strategies aim at increasing the efficacy (through training-dependent plasticity) or the number of connections (sprouting) from supraspinal centers to interneuronal and/or motoneuronal pools located below the lesion site. However, locomotor improvements also can occur without direct projections from the brain beyond the lesion site, through the reorganization of indirect descending pathways and propriospinal connections. Both short and long propriospinal interneurons have been shown to form new intraspinal circuits following SCI. ${ }^{144,145}$ Propriospinal relay connections can bypass the injury site ${ }^{144,146}$ and mediate modest functional recovery ${ }^{147,148}$ even with a total disruption of long descending supraspinal pathways. ${ }^{145}$ Short propriospinal interneurons are more likely to die after SCI, but survivors show transient upregulation of regeneration-associated genes, as well as pro-apoptotic genes. ${ }^{149,150}$ The potential of harnessing the plasticity of propriospinal neurons to improve functional recovery is twofold. Not only do they contribute to the formation of novel relays by receiving input from damaged descending axons and transmitting this information to the caudal cord (see the section "Can step-training guide sprouting and regeneration toward the right target?"), but they can also regenerate into growth-promoting grafts. ${ }^{144,146,151,152}$ Cycling exercise, for example, has been shown to increase propriospinal regeneration into peripheral nerve grafts and modulates the expression of genes associated with regeneration. ${ }^{152}$ Together, these studies suggest that propriospinal interneurons have a remarkable plastic potential and could be utilized to enhance functional recovery with activitybased therapies.

\section{Afferent Feedback and Spinal Reflexes Contribute to Locomotor Recovery}

In addition to changes in the motoneuronal and interneuronal CPG constituents, SCI and step-training also cause profound neuroplastic changes in proprioceptive feedback pathways triggered by the repetitive activation of muscle groups (Fig. 1). Locomotor control is highly dependent on, and driven by, information originating from muscle and cutaneous afferents. ${ }^{153}$ In the absence (or disruption) of supraspinal pathways, the dependence on sensory feedback is dramatically increased after SCI. ${ }^{9,154}$ In a model of complete spinal cord transection, step-training is shown to modulate transmission in reflex pathways originating from group $\mathrm{Ia} / \mathrm{b}$ muscle afferents, ${ }^{13}$ as well as cutaneous afferents ${ }^{14}$ in a complex manner that is contingent on both the origin of the stimulated af- ferents and the specific motor pool activated. It is well known that cutaneous afferents play a critical role in controlling and shaping locomotor movements ${ }^{155}$ and enhanced cutaneous feedback improves locomotor recovery. ${ }^{156-158}$ At least one source of cutaneous feedback originating from the leg/paw is necessary for recovery in spinal cats. ${ }^{159}$ Of all cutaneous feedback, the information originating from the sole of the foot appears to be the most critical ${ }^{14}$ and this has later been shown to be of critical importance in normalizing spinal reflex circuits in SCI individuals. ${ }^{160}$ Changes in the feedback system are critical to locomotor recovery, yet most of this information has yet to find its way into clinical rehabilitation programs.

Most of what we know suggests that treadmill training produces similar re-organization of the reflex circuitry in humans and animal models. While it is not possible to explore direct changes in the activity of motoneurons and interneurons in SCI individuals after BWST, comparisons of reflex responses with spinal animal models can shed light about the similarities in the reflex re-organization. In SCI individuals, BWST contributes to the restoration of the phasedependent modulation of the soleus H-reflex with a clear depression occurring during the swing phase. ${ }^{161-163}$ The modulation persisted after the BWST training sessions ended and was associated with a decrease in the body weight support required and increase in walking speed, although reflex re-organization did not correlate with improvements in overground walking abililty evaluated through clinical assessments. ${ }^{163}$ Locomotor training also normalizes flexor reflexes in SCI individuals: TA flexor reflex is decreased during the stance phase and increased during swing. ${ }^{160,164}$

In addition, locomotor training normalized reciprocal and nonreciprocal inhibition of the soleus H-reflex. Notably, the Ib facilitation of the soleus H-reflex obtained with medial gastrocnemius nerve stimulation in spinal cord-injured individuals returned to the normal Ib inhibition after training when evaluated in the sitting position. During stepping, the Ib inhibition was decreased at early swing and increased at late swing in AIS C, and decreased in early stance in AIS D. ${ }^{165}$ This was similar to the reduction in Ib inhibition seen in ablebodied subjects during the stance phase, ${ }^{166}$ but the reversal from inhibition to excitation seen in the intact cat ${ }^{167,168}$ was absent. It is also interesting that the reflex modulation produced by locomotor training varied based on the amount of spared functions. Although the reflexes could not be evaluated during stepping in the two motor complete subjects (one AIS A and one AIS B), reciprocal inhibition of the soleus H-reflex returned after training, as well as Ib-inhibition, with both reflexes being evaluated in the sitting position in those two subjects. In fact, relatively impressive re-organization of the spinal reflex circuitry can be obtained with sensory locomotor feedback alone. Assisted locomotion alone (using Lokomat robot to move the legs, no BWST) was sufficient to normalize the late and early components of the tibialis anterior response to tibial nerve stimulation in chronic complete SCI individuals. ${ }^{169}$

In SCI animal models, reflex re-organization after SCI and steptraining has been studied via intracellular recording and transmission in muscle and cutaneous pathways to extensor and flexor motoneurons was tested. Monosynaptic excitation evoked by group Ia afferents was decreased by step-training. Its phase-dependent modulation also was restored by step-training during locomotor episodes with peak activity occurring during extension, the depolarized phase of the motoneurons. ${ }^{13}$ Cutaneous transmission also was modulated by step-training, but only in a few specific pathways. ${ }^{14}$ Signal transmission in most pathways was depressed, suggesting that post-SCI hyperexcitable reflexes ${ }^{170,171}$ can be normalized by step-training. Interestingly, one of the pathways that was not depressed but facilitated originated from the sole of the foot 
(medial plantar nerve) and facilitated the response of MG motoneurons, possibly contributing to weight-bearing upon signaling of ground contact. ${ }^{14}$ This type of experiment cannot be repeated in humans but can be indirectly estimated through the EMG responses evoked by nerve stimulation in humans as presented above; however, the difference in methodologies must be considered.

One of the limitations in comparing reflex re-organization due to step-training is that the reflexes in spinal animals are typically measured after the animals have recovered a locomotor pattern so that the modulation of the reflexes during stepping can be evaluated. ${ }^{172-174}$ Although the cutaneous reflexes are modulated in a phase-dependent manner in trained spinal animals, some differences exist, compared with in intact animals. Soleus responses to tibial nerve stimulation in intact cats show a short-term depression and longer latency excitation, while the responses show a shortterm excitation in the trained spinal cats. ${ }^{172}$ In untrained chronic spinal cats, triceps surae stretch reflexes are depressed, ${ }^{175}$ although a number of knee and hip muscles not normally activated by the stretch are recruited in the spinal state. Unfortunately, there are few studies in SCI animal models that have examined the afferent reflex re-organization due to locomotor training. A possible comparison with the clinical work would be to evaluate the reflex at rest (mimicking sitting in human subjects) in SCI animals before training is initiated, and then re-examining the same reflex at rest after training.

\section{Greater Dependence of the Locomotor Centers on Descending Systems in Humans}

Amelioration in the locomotor patterns of incomplete SCI individuals following BWST includes an increase in EMG activity and a decrease in burst duration and cocontractions. ${ }^{176,177}$ Gorassini and colleagues point out that the improvement in EMG activity is greater in muscles that receive more cortical projections (i.e., tibialis anterior [TA] and hamstrings), compared with muscles mainly under the influence of local spinal circuits (i.e., soleus). ${ }^{176}$ It is argued that there may be a reinforcement of the remaining cortical and/or brainstem projections, a point that also is supported by the fact that the individuals more responsive to BWST were the ones with the highest remaining motor score for lower limb muscles. ${ }^{178}$ These observations complement results in contused rats for which the recovery of locomotor function with step-training was largely dependent on spared supraspinal pathways. ${ }^{179}$

While firing of primary motor cortex neurons remains largely unmodulated during unobstructed walking in cats, ${ }^{180}$ the synchrony between cortical electroencephalography signals and EMG activity of the TA during walking in humans show coherence between the two signals, indicating that primary motor cortex (directly or through the corticobulbar/bulbospinal pathways) is involved in the control of level unobstructed walking in humans. ${ }^{181}$ This supplies additional support for a greater dependence on cortical command for locomotion in the human spinal cord. It has been shown, for example, that stimulating the CST in chronic incomplete but ambulatory SCI individuals can improve gait ${ }^{182}$ and diminish spasticity. ${ }^{183,184}$ In addition, a training regimen that targets improving voluntary ankle dorsiflexion in incomplete SCI (as compared with training the soleus H-reflex) increases the walking distance on a 2min walk test and the dorsiflexor muscle test score, ${ }^{185}$ supporting the notion that improvements in the control of descending commands may contribute more to recovery than afferent feedback training in humans. ${ }^{186}$ However, improvements in voluntary motor control do not always translate to improvements in walking ability in larger cohorts. In a prospective study, larger gains in lower extremity scores with locomotor training were only weakly correlated to gait speed and distance. ${ }^{187}$ Other factors, such as time since injury, spasticity, and walking ability before training onset, have been shown to be better predictors of improvements in walking speed following locomotor training in a small prospective study in motor incomplete SCI individuals. ${ }^{188}$

Most of the clinical work in testing the influence of supraspinal tracts has been conducted using transcranial magnetic stimulation (TMS) over the motor cortex, which leads to preferential activation of the CST. However, the potential contribution of spared extrapyramidal pathways to the state of excitability of the spinal circuitry has not been explored thoroughly. It is known from galvanic stimulation of the vestibular system in incomplete SCI subjects that transmission in this pathway, as measured by the soleus muscle response to the galvanic stimulation, is relatively well correlated with balance test and moderately well to some gait function. ${ }^{189}$ Studies showing greater activity in the cerebellar regions over the sensorimotor cortical regions following BWST in incomplete SCI humans ${ }^{188}$ provide further evidence that sub-cortical systems and projections from the brainstem nuclei to the spinal cord may play a greater role in recovery than traditionally recognized. In those individuals, measures of locomotor recovery correlated better with cerebellar activation than with cortical activation. The cerebellar plasticity associated with sensorimotor training also serves as a reminder that ascending tracts, whether spinothalamic or spinocerebellar, are likely participants in the recovery observed with BWST in incomplete SCI individuals. Variations in the damage to sensory tracts may be as important as variations in the motor tracts in determining the outcome, although spared sensory pathways have been relatively unexplored.

Most of our knowledge about the contribution of varying tracts to locomotion comes from lesion studies that show a number of similarities between species but also some important differences. Differences in the role and compensatory ability of spinal tracts are revealed between human and non-human mammals following partial injury. ${ }^{190}$ Injuries to the CST or even the entire dorsal columns and dorsolateral columns have little effect on locomotion in cats and nonhuman primates. Bilateral lesions to the dorsolateral funiculi and dorsal column cause little more than a paw drag during swing in cats $^{191}$ and lesions to the pyramidal/CST tract at the brainstem or spinal level have limited effects on locomotion in monkeys. ${ }^{192-194}$ Humans, on the other hand, are much more susceptible to injuries to the lateral CST. Cordotomies performed for pain relief in cancer patients show that bilateral damage to the posterior lateral quadrant at the thoracic level essentially renders the patient paraplegic. ${ }^{195}$

It seems that in non-human mammals, the ventral tracts (most notably the vestibulospinal and reticulospinal) can compensate for damage to the lateral CST and rubrospinal tracts, but this compensation does not occur in humans. In cats, spared ventrolateral pathways will allow recovery of locomotion after injury to the dorsolateral CST/rubrospinal tracts, albeit with an increased paw drag during swing and a change in the timing of activation for certain muscles. ${ }^{191}$ Spared dorsolateral pathways will also lead to recovery of locomotion after injury to the ventrolateral reticulospinal and vestibulospinal pathways, although interlimb coordination will be affected. ${ }^{196-199}$ Evidence in non-human primates is limited but suggests a greater role for the reticulospinal and vestibulospinal pathways in locomotion. "Medial system" lesions, ${ }^{200}$ which damage most of the reticulospinal and vestibulospinal pathways, produces deficits in posture and walking with only one of four monkeys able to walk across the floor after a long 
recovery period. Surprisingly, Nathan reports little to no motor deficits in humans following a ventrolateral cordotomy, indicating that the dorsolateral funiculus tracts can compensate for damage in the ventrolateral tracts in humans. ${ }^{195}$

In summary, although vestibulo- and reticulospinal tracts are important for the initiation of locomotion, it appears that the lateral CST can compensate for damage to the ventrolateral funiculi tracts in humans and non-human mammals, but that humans are particularly dependent on the CST for locomotion, compared with nonhuman primates and other mammals.

While it is evident that spared descending systems are important determinants in locomotor recovery and likely contribute to the beneficial effect of step-training, assessing the residual transmission in spared pathways remains technically challenging in humans. ${ }^{189}$ The effect of locomotor training on transmission through these pathways is still largely unexplored. The limited clinical evidence suggests that training enhances the excitatory influence of descending pathways recruited by motor cortex TMS and the excitability of inhibitory spinal networks: the inhibition of the common peroneal nerve on TA TMS response is increased after locomotor training in incomplete SCI individuals, as is the inhibitory components of the tibial nerve reflex on the TA. ${ }^{201}$ Recent results with epidural or transcutaneous spinal cord stimulation ${ }^{37,183,202,203}$ in complete and incomplete SCI individuals demonstrate an enhancement of locomotor activity with stimulation of the dorsal aspect of the lumbar cord. These studies have uncovered a latent volitional control of muscles paralyzed with no evidence of twitch or EMG activity prior to the stimulation being applied. ${ }^{204}$ The elements activated by the stimulation would involve low threshold dorsal root afferents (proprioceptive and cutaneous) that could in turn activate spinal interneurons to reduce the activation threshold of the locomotor circuitry, allow the few remaining descending fibers to control the activation of the circuitry, and improve the appropriate phase-dependent modulation of the locomotor circuitry by afferent feedback. ${ }^{202,203,205}$

\section{Potential Role of Locomotor Training in Promoting Axonal Sprouting and Growth}

Anatomical plasticity studies in response to injury have mainly focused on axonal growth after SCI, regeneration/sprouting/ synaptogenesis, formation of novel relays, and strengthening of existing pathways. Providing a more permissive environment (e.g., cellular transplants or peripheral nerve graft) can promote some regeneration and sprouting, leading to reorganization of the spinal cord circuitry that may improve recovery. Injury-induced sprouting has been shown to be enhanced by activity such as the stimulation of descending pathways and by activity including treadmill training. ${ }^{206}$

The CST has received the most attention, presumably because of its importance in hand function and also because of its recalcitrance to regeneration. Other pathways that respond more robustly to injury might provide more interesting information. ${ }^{146,207,208}$ Electrical stimulation of the motor cortex promotes CST sprouting and recovery of function, and also elicits sprouting from motor cortex to other targets (e.g., red nucleus) that in turn can stimulate sprouting of rubrospinal axons. ${ }^{209,210}$ Sprouting into the spinal cord from supraspinal areas-including the motor cortex, ${ }^{211}$ red nucleus, ${ }^{207}$ reticular formation, ${ }^{146}$ and raphe ${ }^{212}$ — can be evoked by incomplete SCI. Sprouting in primates is surprisingly more extensive than in smaller animals after hemisection but recovery of function is better in smaller animals. ${ }^{50,51,59}$ To date, there is no convincing data supporting a role for locomotor training in increasing the regenerative potential and improving function in SCI models of regenera- tion. ${ }^{213-216}$ The understanding of how axonal growth is regulated in adult animal models remains largely unknown ${ }^{217}$ and needs to be evaluated in terms of maladaptive, as well as beneficial effects.

\section{From Step-Training Dependent Plasticity to Functional Recovery: The Ultimate Challenge of Molecular Correlates}

The training-dependent increase in neuronal activity is ultimately transduced at the cellular and molecular level into functional recovery. However, specific cellular mechanisms responsible for spinal cord activity-dependent learning remain largely unknown (Fig. 1). Multiple descending tracts have a significant role both in the initiation and the control of locomotion, including glutamatergic, noradrenergic, dopaminergic, and serotoninergic pathways. Early studies have focused on the loss of monoaminergic spinal projections (5-HT, NA) following SCI and the activitydependent plasticity in these systems following step-training, essentially due to their involvement in the control (initiation and maintenance) of locomotion. ${ }^{218}$ Step-training triggers a reorganization of synaptic inputs to spinal motoneurons below the injury, with a net decrease in the inhibitory influence associated with successful locomotor recovery. ${ }^{219}$ A general increase in synaptic input to motoneurons, ${ }^{220}$ a selective increase in cholinergic input, and a decrease in the expression of $\mathrm{GABA}_{\mathrm{A}}$ receptor gamma 2 subunit to extensor motoneurons ${ }^{221,222}$ also are reported. This suggests a high degree of specificity in the changes triggered by locomotor training but fails to clearly identify how locomotor training translates into functional recovery.

Spinal motoneurons express a wide variety of 5-HT receptors ${ }^{223}$ and 5-HT release increases in the ventral horn during locomotion. ${ }^{224}$ The majority of locomotor-activated interneurons also colocalize with $5-\mathrm{HT}_{7}, 5-\mathrm{HT}_{2 \mathrm{~A}}$, and 5- $\mathrm{HT}_{1 \mathrm{~A}}$ receptors. ${ }^{225}$ Locomotor recovery after a chronic $\mathrm{SCI}$ is facilitated by exogenous application of 5-HT or 5- $\mathrm{HT}_{2}$ and 5- $\mathrm{HT}_{7}$ receptor agonists and embryonic 5-HT grafts after chronic SCI in adult rats ${ }^{226-232}$ and cats, ${ }^{233,234}$ and the complex modulation of motoneuronal intrinsic properties by 5 -HT has been extensively described. ${ }^{223}$ The activation of $5-\mathrm{HT}_{2 \mathrm{~A}}$ receptors in the spinal cord enhances spinal excitability and facilitates locomotor networks activity. ${ }^{235,236}$ Wheel running following an incomplete SCI stimulates serotoninergic fibers regrowth and improves locomotor recovery. ${ }^{237}$

In the human spinal cord, serotoninergic processes have been identified within the ventral horn surrounding motoneurons, as well as in the intermediolateral region, ${ }^{238}$ similar to what is reported for rodents and non-human primates. The lack of monoamines after SCI is clearly detrimental for locomotor performance and providing exogenous monoamines to improve recovery definitely has potential for success, at least in animal models. However, its systemic administration to SCI individuals leads to significant unwanted side effects and also can be associated with psychiatric disorders $^{239}$ depending on the type of receptor targeted. In addition, serotonin selective re-uptake inhibitors were shown to augment strength, but also spasticity and spasms, and did little, if anything, to improve locomotor function in incomplete SCI individuals. ${ }^{240,241}$ While this pathway was first identified as being promising, its critical involvement in spasticity and serious side effects raises the question as to whether it really is an appropriate target.

Neurotrophins, in particular brain-derived neurotrophic factor (BDNF), play a critical role in adaptive plasticity in the nervous system and contribute to restoring function following SCI. BDNF has a widespread and complex effect ranging from cell survival to 
increased nociception. It is also a potent neuromodulator that significantly impacts synaptic strength in the spinal cord. ${ }^{242}$ It can be produced in an activity-dependent manner by a variety of nonneuronal cells in the nervous system including Schwann cells in the periphery and microglia in the dorsal horn of the spinal cord, which contribute to robust nerve regeneration ${ }^{243}$ and nociception, respectively. ${ }^{244}$ An important pathway for transducing the effect of locomotor training is de novo BDNF synthesis. The expression of BDNF in the spinal cord of rodents is significantly increased in response to locomotor training with protein and messenger RNA levels correlated with the intensity and volume of training and also to the extent of functional recovery. ${ }^{4,54,245,246} \mathrm{BDNF}$ serum levels also correlate with the intensity and volume of exercise in humans, ${ }^{247,248}$ but it remains unclear if this is also the case for SCI individuals.

Exogenous BDNF increases the activity of neurons in the locomotor circuitry. After a complete thoracic SCI, delivery of neurotrophins promotes locomotor recovery in rats and cats, even in the absence of step-training. ${ }^{56,62,249-251}$ Interneurons of the L2 intermediate zone of the BDNF-treated animals displayed an increased expression of the transcription factor c-Fos, a marker of neuronal activity, indicating an augmented activation of interneurons in the vicinity of the locomotor $\mathrm{CPG} .{ }^{62}$ It remains unknown if the enhanced activation of interneurons is generalized or restricted to a specific subgroup of interneurons. BDNF delivery also causes an increased excitability of motoneurons after SCI as evidenced by a reduced rheobase. ${ }^{62}$ However, step-training does not similarly modulate rheobase but rather decreases the AHP and increases monosynaptic EPSPs. ${ }^{242,252}$ Although some specific details differ, the similarity between the functional recovery triggered by step-training and by BDNF delivery further supports the idea that the step-trainingdependent increase in BDNF levels is a critical player in locomotor recovery. It is noteworthy that the relationship between BDNF, stepping, nociception, and spasticity is complex after $\mathrm{SCI}^{253}$ and that great care will be required so as not to improve motor recovery at the cost of increasing pain and spasticity. The complexity of spinal cord physiology after SCI is not sufficiently addressed in the field. BDNF is certainly not the only one molecule impacting different systems in a conflicting fashion, and it should be recognized that manipulating a single molecule to treat all SCIs is unlikely to have significant and predicable effects. This needs to be better addressed for a more successful translation of treatments to the clinic.

Several inhibitory pathways driven by GABA/glycine are impaired in SCI individuals, including reciprocal inhibition, ${ }^{254,255} \mathrm{Ib}$ inhibition, ${ }^{256}$ and presynaptic inhibition. ${ }^{257-259}$ These reflexes influence and shape the locomotor pattern. ${ }^{260}$ Reduced spinal inhibition also has detrimental consequences on locomotor activity. ${ }^{261-263}$ Despite the apparent hyperexcitability in spinal pathways, the "inhibitory potential" of the spinal cord was reported to be increased after SCI. ${ }^{263-266}$ How can we reconcile a clear lack of inhibition as displayed by spasms, clonus, and exaggerated reflexes and an increased presence of biological markers of inhibition (GAD67, gephyrin, GABA $\mathrm{A}$ ) $?^{9,222,265,266}$ Normal GABA $\mathrm{R}$ function is critically dependent on $\left[\mathrm{Cl}^{-}\right]_{\mathrm{i}}$, which is largely determined by the relative expression of two cation chloride cotransporters in neurons, the inwardly directed $\mathrm{Na}^{+}-\mathrm{K}^{+}-\mathrm{Cl}^{-}$ cotransporter isoform 1 (NKCC1) and the chloride-extruding $\mathrm{K}^{+}$$\mathrm{Cl}^{-}$cotransporter isoform 2 (KCC2). ${ }^{267,268}$ An elegant study established that the loss of spinal inhibition resulted not only from the lack of descending inhibition due to the disruption of supraspinal tracts, but also from the collapse in GABAergic activity mediated by a downregulation of KCC 2 in spinal motoneurons. ${ }^{269}$ The disruption in chloride homeostasis after SCI is associated with chronic pain and spasticity. The strength of postsynaptic inhibition is reduced and excitability increased due to a downregulation of KCC2 in neurons of the superficial layers of the dorsal horn ${ }^{270,271}$ and in the motoneuronal membrane of the ventral horn, ${ }^{269,272,273}$ causing a depolarizing shift in the chloride equilibrium potential.

Given the beneficial effect of BDNF and 5-HT on functional recovery after SCI, it is not surprising that they both have the potential to modulate $\mathrm{KCC} 2$ expression and contribute to the restoration of chloride homeostasis after SCI. KCC2 expression is tightly controlled by neuronal activity. ${ }^{274}$ This regulation involves BDNF, neuronal intrinsic activity, or activity of excitatory synapses. ${ }^{275-278}$ A single dose of BDNF after SCI increases the expression of KCC2 in motoneurons. ${ }^{269}$ Similarly, exercise increases KCC2 levels in the spinal cord after SCI in a BDNF-dependent manner and contributes to the suppression of spasticity and allodynia. ${ }^{273,279,280}$ Recent studies also show that activation of $5-\mathrm{HT}_{2 \mathrm{~A}}$ receptors can shift the chloride equilibrium potential in the hyperpolarizing direction ${ }^{272}$ through an upregulation of KCC2 function.

The pharmacological treatments currently available for spasticity have serious side effects since they act upstream of $N$-methylD-aspartate and $\mathrm{Ca}^{2+}$-dependent mechanisms. Baclofen, for example, is routinely used to treat spasticity, but it produces a deep and long-lasting depression of spinal excitability ${ }^{281,282}$ and weakens the muscle force generated by the more fatigable motor units. $^{283}$ Although it is certainly beneficial to decrease the recruitment of inappropriately active muscles, it also interferes with motor recovery. Direct therapeutic treatment to counteract disruption of chloride homeostasis would restore endogenous inhibition rather than actively depress excitability. Current data suggest that beyond pharmacological avenues, step-training also has the potential to target this pathway.

\section{Conclusion}

SCI creates a complex set of multilayered complications and disruptions that create the need for rehabilitation programs that involve many targets and processes (motoneurons, interneurons, sprouting, etc.; Fig. 1). Some of the treatments developed in animal models have shown positive but limited results in SCI individuals with better results obtained when a combination of strategies were utilized. An interesting conclusion made by Eidelberg and colleagues after failing to initiate stepping in spinal monkeys using methods that were effective in spinal cats was that "step generators do exist in primates, but their access to skeleton-motor neurons may depend, more heavily than in cats, upon the presence of tonic descending facilitatory influences." ${ }^{194}$ The limited locomotor recovery seen with BWST in SCI individuals may be an indication that the spinal locomotor centers are more depressed in humans than they are in animals, and/or more dependent on a tonic excitatory supraspinal drive. This would explain the high correlation between the degree of meaningful recovery and amount and type of spared descending input. New analyses indicate remarkably greater sprouting and probably a larger interneuron pool in primates than in rodents. It is difficult to assess the extent to which relative differences in the number or type of propriospinal neurons and networks in small versus large animals are not simply related to scale. ${ }^{67}$ This large untapped interneuron pool and increased sprouting capability suggest that focusing on interneuronal populations as potential targets for spared descending tracts sprouting, as well as task-appropriate proprioceptive feedback to increase recovery of function, is probably key.

Strategies for achieving functional motor improvement for severe SCI individuals will probably require task specific training 
with enhanced proprioceptive feedback and some form of nextgeneration spinal cord stimulation and pharmacological treatments. Our ability to project translatable data from animal models using new techniques will continue to be impaired by the relatively few studies directly comparing species differences.

\section{Acknowledgments}

This work was supported by the National Institute of Neurological Disorders and Stroke Grants NS-083666 (MPC) and NS055976 (ML), the National Institute of Biomedical Imaging and Bioengineering Grant EB-012855 (ML) and the Craig H. Neilsen Foundation (MPC). The authors would like to acknowledge Maria Knikou, Kim Dougherty, and Michael A. Lane for their comments on an earlier version of this manuscript.

\section{Author Disclosure Statement}

No competing financial interests exist.

\section{References}

1. Cai, L.L., Courtine, G., Fong, A.J., Burdick, J.W., Roy, R.R., and Edgerton, V.R. (2006). Plasticity of functional connectivity in the adult spinal cord. Philos. Trans. R. Soc. Lond B Biol. Sci. 361, 16351646.

2. Fong, A.J., Cai, L.L., Otoshi, C.K., Reinkensmeyer, D.J., Burdick, J.W., Roy, R.R., and Edgerton, V.R. (2005). Spinal cord-transected mice learn to step in response to quipazine treatment and robotic training. J. Neurosci. 25, 11738-11747.

3. Timoszyk, W.K., Nessler, J.A., Acosta, C., Roy, R.R., Edgerton, V.R., Reinkensmeyer, D.J., and de, Leon, R. (2005). Hindlimb loading determines stepping quantity and quality following spinal cord transection. Brain Res. 1050, 180-189.

4. Cha, J., Heng, C., Reinkensmeyer, D.J., Roy, R.R., Edgerton, V.R., and De Leon, R.D. (2007). Locomotor ability in spinal rats is dependent on the amount of activity imposed on the hindlimbs during treadmill training. J. Neurotrauma 24, 1000-1012.

5. Lovely, R.G., Gregor, R.J., Roy, R.R., and Edgerton, V.R. (1986). Effects of training on the recovery of full-weight-bearing stepping in the adult spinal cat. Exp.Neurol. 92, 421-435.

6. Barbeau, H. and Rossignol, S. (1987). Recovery of locomotion after chronic spinalization in the adult cat. Brain Res. 412, 84-95.

7. De Leon, R.D., Hodgson, J.A., Roy, R.R., and Edgerton, V.R. (1998). Full weight-bearing hindlimb standing following stand training in the adult spinal cat. J. Neurophysiol. 80, 83-91.

8. De Leon, R.D., Hodgson, J.A., Roy, R.R., and Edgerton, V.R. (1998). Locomotor capacity attributable to step training versus spontaneous recovery after spinalization in adult cats. J. Neurophysiol. 79, 1329-1340.

9. Edgerton, V.R., Leon, R.D., Harkema, S.J., Hodgson, J.A., London, N., Reinkensmeyer, D.J., Roy, R.R., Talmadge, R.J., Tillakaratne, N.J., Timoszyk, W., and Tobin, A. (2001). Retraining the injured spinal cord. J. Physiol. 533, 15-22.

10. Edgerton, V.R., Roy, R.R., DeLeon, R., Tillakaratne, N., and Hodgson, J.A. (1997). Does motor learning occur in the spinal cord? Neuroscientist 3, 287-294.

11. Martinez, M., Delivet-Mongrain, H., Leblond, H., and Rossignol, S. (2012). Incomplete spinal cord injury promotes durable functional changes within the spinal locomotor circuitry. J. Neurophysiol. 108, 124-134.

12. Rossignol, S., Martinez, M., Escalona, M., Kundu, A., DelivetMongrain, H., Alluin, O., and Gossard, J.P. (2015). The "beneficial" effects of locomotor training after various types of spinal lesions in cats and rats. Prog. Brain Res. 218, 173-198.

13. Côté, M.P., Ménard, A., and Gossard, J.P. (2003). Spinal cats on the treadmill: changes in load pathways. J. Neurosci. 23, 2789-2796.

14. Côté, M.P. and Gossard, J.P. (2004). Step training-dependent plasticity in spinal cutaneous pathways. J. Neurosci. 24, 11317-11327.

15. Takeoka, A., Vollenweider, I., Courtine, G., and Arber, S. (2014). Muscle spindle feedback directs locomotor recovery and circuit reorganization after spinal cord injury. Cell 159, 1626-1639.
16. Harkema, S.J., Hurley, S.L., Patel, U.K., Requejo, P.S., Dobkin, B.H., and Edgerton, V.R. (1997). Human lumbosacral spinal cord interprets loading during stepping. J. Neurophysiol. 77, 797-811.

17. Van de Crommert, H.W., Mulder, T., and Duysens, J. (1998). Neural control of locomotion: sensory control of the central pattern generator and its relation to treadmill training. Gait Posture 7, 251-263.

18. Wernig, A., Nanassy, A., and Muller, S. (1998). Maintenance of locomotor abilities following Laufband (treadmill) therapy in paraand tetraplegic persons: follow-up studies. Spinal Cord 36, 744-749.

19. Behrman, A.L., Lawless-Dixon, A.R., Davis, S.B., Bowden, M.G., Nair, P., Phadke, C., Hannold, E.M., Plummer, P., and Harkema, S.J. (2005). Locomotor training progression and outcomes after incomplete spinal cord injury. Phys.Ther. 85, 1356-1371.

20. Behrman, A.L. and Harkema, S.J. (2000). Locomotor training after human spinal cord injury: a series of case studies. Phys.Ther. 80, 688-700.

21. Dietz, V. and Harkema, S.J. (2004). Locomotor activity in spinal cord-injured persons. J. Appl. Physiol. 96, 1954-1960.

22. Field-Fote, E.C. and Roach, K.E. (2011). Influence of a locomotor training approach on walking speed and distance in people with chronic spinal cord injury: a randomized clinical trial. Phys. Ther. 91, $48-60$.

23. Dobkin, B.H., Harkema, S., Requejo, P., and Edgerton, V.R. (1995). Modulation of locomotor-like EMG activity in subjects with complete and incomplete spinal cord injury. J. Neurol. Rehabil. 9, 183190.

24. Dietz, V., Muller, R., and Colombo, G. (2002). Locomotor activity in spinal man: significance of afferent input from joint and load receptors. Brain 125, 2626-2634.

25. Forrest, G.F., Sisto, S.A., Barbeau, H., Kirshblum, S.C., Wilen, J., Bond, Q., Bentson, S., Asselin, P., Cirnigliaro, C.M., and Harkema, S. (2008). Neuromotor and musculoskeletal responses to locomotor training for an individual with chronic motor complete AIS-B spinal cord injury. J. Spinal Cord Med. 31, 509-521.

26. Thompson, A.K. and Wolpaw, J.R. (2014). Operant conditioning of spinal reflexes: from basic science to clinical therapy. Front. Integr. Neurosci. 8, 25 .

27. Thompson, A.K. and Wolpaw, J.R. (2015). Restoring walking after spinal cord injury: operant conditioning of spinal reflexes can help. Neuroscientist 21, 203-215.

28. Chen, X.Y., Carp, J.S., Chen, L., and Wolpaw, J.R. (2002). Corticospinal tract transection prevents operantly conditioned H-reflex increase in rats. Exp. Brain Res. 144, 88-94.

29. Chen, Y., Chen, X.Y., Jakeman, L.B., Schalk, G., Stokes, B.T., and Wolpaw, J.R. (2005). The interaction of a new motor skill and an old one: H-reflex conditioning and locomotion in rats. J. Neurosci. 25, 6898-6906.

30. Chen, Y., Chen, X.Y., Jakeman, L.B., Chen, L., Stokes, B.T., and Wolpaw, J.R. (2006). Operant conditioning of H-reflex can correct a locomotor abnormality after spinal cord injury in rats. J. Neurosci. 26, 12537-12543.

31. Smith, R.R., Brown, E.H., Shum-Siu, A., Whelan, A., Burke, D.A., Benton, R.L., and Magnuson, D.S. (2009). Swim training initiated acutely after spinal cord injury is ineffective and induces extravasation in and around the epicenter. J. Neurotrauma 26, 1017-1027.

32. Detloff, M.R., Smith, E.J., Quiros Molina, D., Ganzer, P.D., and Houle, J.D. (2014). Acute exercise prevents the development of neuropathic pain and the sprouting of non-peptidergic (GDNF- and artemin-responsive) c-fibers after spinal cord injury. Exp. Neurol. $255,38-48$.

33. Dimitrijevic, M.R., Gerasimenko, Y., and Pinter, M.M. (1998). Evidence for a spinal central pattern generator in humans Neural control of stereotypic limb movements. Ann. N. Y. Acad. Sci. 860, 360-376.

34. Cazalets, J.R., Borde, M., and Clarac, F. (1995). Localization and organization of the central pattern generator for hindlimb locomotion in newborn rat. J. Neurosci. 15, 4943-4951.

35. Shik, M.L., Severin, F.V., and Orlovskii, G.N. (1966). [Control of walking and running by means of electric stimulation of the midbrain]. Biofizika 11, 659-666.

36. Gerasimenko, Y., Roy, R.R., and Edgerton, V.R. (2008). Epidural stimulation: comparison of the spinal circuits that generate and control locomotion in rats, cats and humans. Exp. Neurol. 209, 417-425.

37. Harkema, S., Gerasimenko, Y., Hodes, J., Burdick, J., Angeli, C., Chen, Y., Ferreira, C., Willhite, A., Rejc, E., Grossman, R.G., and Edgerton, 
V.R. (2011). Effect of epidural stimulation of the lumbosacral spinal cord on voluntary movement, standing, and assisted stepping after motor complete paraplegia: a case study. Lancet 377, 1938-1947.

38. Musienko, P., van den Brand, R., Marzendorfer, O., Roy, R.R., Gerasimenko, Y., Edgerton, V.R., and Courtine, G. (2011). Controlling specific locomotor behaviors through multidimensional monoaminergic modulation of spinal circuitries. J. Neurosci. 31, 9264-9278.

39. Musienko, P., van den Brand, R., Maerzendorfer, O., Larmagnac, A., and Courtine, G. (2009). Combinatory electrical and pharmacological neuroprosthetic interfaces to regain motor function after spinal cord injury. I.E.E.E. Trans. Biomed. Eng. 56, 2707-2711.

40. Kim, D., Adipudi, V., Shibayama, M., Giszter, S., Tessler, A., Murray, M., and Simansky, K.J. (1999). Direct agonists for serotonin receptors enhance locomotor function in rats that received neural transplants after neonatal spinal transection. J. Neurosci. 19, 62136224.

41. Nothias, J.M., Mitsui, T., Shumsky, J.S., Fischer, I., Antonacci, M.D., and Murray, M. (2005). Combined effects of neurotrophin secreting transplants, exercise, and serotonergic drug challenge improve function in spinal rats. Neurorehabil. Neural Repair 19, 296-312.

42. Rossignol, S., Chau, C., Brustein, E., Giroux, N., Bouyer, L., Barbeau, H., and Reader, T.A. (1998). Pharmacological activation and modulation of the central pattern generator for locomotion in the cat. Ann. N. Y. Acad. Sci. 860, 346-359.

43. Rossignol, S., Chau, C., Giroux, N., Brustein, E., and Reader, T. (2001). Locomotor recovery in the cat: plasticity and pharmacology. In: Basic motor control to functional recovery II. Gantchev, N. (ed). St. Kliment Ohridski University Press: Sofia, Bulgaria, pps. 1-4.

44. Tabakow, P., Jarmundowicz, W., Czapiga, B., Fortuna, W., Miedzybrodzki, R., Czyz, M., Huber, J., Szarek, D., Okurowski, S., Szewczyk, P., Gorski, A., and Raisman, G. (2013). Transplantation of autologous olfactory ensheathing cells in complete human spinal cord injury. Cell Transplant. 22, 1591-1612.

45. Tabakow, P., Raisman, G., Fortuna, W., Czyz, M., Huber, J., Li, D., Szewczyk, P., Okurowski, S., Miedzybrodzki, R., Czapiga, B., Salomon, B., Halon, A., Li, Y., Lipiec, J., Kulczyk, A., and Jarmundowicz, W. (2014). Functional regeneration of supraspinal connections in a patient with transected spinal cord following transplantation of bulbar olfactory ensheathing cells with peripheral nerve bridging. Cell Transplant. 23, 1631-1655.

46. Kaas, J.H., Qi, H.X., Burish, M.J., Gharbawie, O.A., Onifer, S.M., and Massey, J.M. (2008). Cortical and subcortical plasticity in the brains of humans, primates, and rats after damage to sensory afferents in the dorsal columns of the spinal cord. Exp. Neurol. 209, 407-416.

47. Liao, C.C., DiCarlo, G.E., Gharbawie, O.A., Qi, H.X., and Kaas, J.H. (2015). Spinal cord neuron inputs to the cuneate nucleus that partially survive dorsal column lesions: a pathway that could contribute to recovery after spinal cord injury. J. Comp. Neurol. 523, 2138-2160.

48. Darian-Smith, C. (2004). Primary afferent terminal sprouting after a cervical dorsal rootlet section in the macaque monkey. J. Comp. Neurol. 470, 134-150.

49. Darian-Smith, C., Hopkins, S., and Ralston, H.J., 3rd. (2010). Changes in synaptic populations in the spinal dorsal horn following a dorsal rhizotomy in the monkey. J. Comp. Neurol. 518, 103-117.

50. Darian-Smith, C., Lilak, A., and Alarcon, C. (2013). Corticospinal sprouting occurs selectively following dorsal rhizotomy in the macaque monkey. J. Comp. Neurol. 521, 2359-2372.

51. Rosenzweig, E.S., Courtine, G., Jindrich, D.L., Brock, J.H., Ferguson, A.R., Strand, S.C., Nout, Y.S., Roy, R.R., Miller, D.M., Beattie, M.S., Havton, L.A., Bresnahan, J.C., Edgerton, V.R., and Tuszynski, M.H. (2010). Extensive spontaneous plasticity of corticospinal projections after primate spinal cord injury. Nat. Neurosci. 13, 1505-1510.

52. Swanson, L.W. (1995). Mapping the human brain: past, present, and future. Trends Neurosci. 18, 471-474.

53. Leblond, H., L'Esperance, M., Orsal, D., and Rossignol, S. (2003). Treadmill locomotion in the intact and spinal mouse. J. Neurosci. 23, 11411-11419.

54. Côté, M.-P., Azzam, G.A., Lemay, M.A., Zhukareva, V., and Houle, J.D. (2011). Activity-dependent increase in neurotrophic factors is associated with an enhanced modulation of spinal reflexes after spinal cord injury. J. Neurotrauma 28, 299-309.

55. Alluin, O., Delivet-Mongrain, H., and Rossignol, S. (2015). Inducing hindlimb locomotor recovery in adult rat after complete thoracic spinal cord section using repeated treadmill training with perineal stimulation only. J. Neurophysiol. 114, 1931-1946.
56. Boyce, V.S., Tumolo, M., Fischer, I., Murray, M., and Lemay, M.A (2007). Neurotrophic factors promote and enhance locomotor recovery in untrained spinalized cats. J. Neurophysiol. 98, 1988-1996.

57. Lee, J.H., Jones, C.F., Okon, E.B., Anderson, L., Tigchelaar, S., Kooner, P., Godbey, T., Chua, B., Gray, G., Hildebrandt, R., Cripton, P., Tetzlaff, W., and Kwon, B.K. (2013). A novel porcine model of traumatic thoracic spinal cord injury. J. Neurotrauma 30, 142-159.

58. Friedli, L., Rosenzweig, E.S., Barraud, Q., Schubert, M., Dominici, N., Awai, L., Nielson, J.L., Musienko, P., Nout-Lomas, Y., Zhong, H., Zdunowski, S., Roy, R.R., Strand, S.C., van den Brand, R., Havton, L.A., Beattie, M.S., Bresnahan, J.C., Bezard, E., Bloch, J., Edgerton, V.R., Ferguson, A.R., Curt, A., Tuszynski, M.H., and Courtine, G. (2015). Pronounced species divergence in corticospinal tract reorganization and functional recovery after lateralized spinal cord injury favors primates. Sci. Transl. Med. 7, 302ra134.

59. Darian-Smith, C., Lilak, A., Garner, J., and Irvine, K.A. (2014). Corticospinal sprouting differs according to spinal injury location and cortical origin in macaque monkeys. J. Neurosci. 34, 12267-12279.

60. Kakulas, B.A. (2004). Neuropathology: the foundation for new treatments in spinal cord injury. Spinal Cord 42, 549-563.

61. McKay, W.B., Lim, H.K., Priebe, M.M., Stokic, D.S., and Sherwood, A.M. (2004). Clinical neurophysiological assessment of residual motor control in post-spinal cord injury paralysis. Neurorehabil. Neural Repair 18, 144-153.

62. Boyce, V.S., Park, J., Gage, F.H., and Mendell, L.M. (2012). Differential effects of brain-derived neurotrophic factor and neurotrophin-3 on hindlimb function in paraplegic rats. Eur. J. Neurosci. 35, 221-232.

63. Willenberg, R. and Steward, O. (2015). Nonspecific labeling limits the utility of Cre-Lox bred CST-YFP mice for studies of corticospinal tract regeneration. J. Comp. Neurol. 523, 2665-2682.

64. Yang, J.F. and Gorassini, M. (2006). Spinal and brain control of human walking: implications for retraining of walking. Neuroscientist $12,379-389$.

65. Hansen, C.N., Faw, T.D., White, S., Buford, J.A., Grau, J.W., and Basso, D.M. (2016). Sparing of descending axons rescues interneuron plasticity in the lumbar cord to allow adaptive learning after thoracic spinal cordinjury. Front. Neural Circuits 10, 11.

66. Ni, Y., Nawabi, H., Liu, X., Yang, L., Miyamichi, K., Tedeschi, A., Xu, B., Wall, N.R., Callaway, E.M., and He, Z. (2014). Characterization of long descending premotor propriospinal neurons in the spinal cord. J. Neurosci. 34, 9404-9417.

67. Bjugn, R. and Gundersen, H.J. (1993). Estimate of the total number of neurons and glial and endothelial cells in the rat spinal cord by means of the optical disector. J. Comp. Neurol. 328, 406-414.

68. Gorgey, A.S. and Dudley, G.A. (2007). Skeletal muscle atrophy and increased intramuscular fat after incomplete spinal cord injury. Spinal Cord 45, 304-309.

69. Castro, M.J., Apple, D.F., Jr., Hillegass, E.A., and Dudley, G.A. (1999). Influence of complete spinal cord injury on skeletal muscle cross-sectional area within the first 6 months of injury. Eur. J. Appl. Physiol. Occup. Physiol. 80, 373-378.

70. Dudley-Javoroski, S. and Shields, R.K. (2008). Muscle and bone plasticity after spinal cord injury: review of adaptations to disuse and to electrical muscle stimulation. J. Rehabil. Res. Dev. 45, 283-296.

71. Burnham, R., Martin, T., Stein, R., Bell, G., MacLean, I., and Steadward, R. (1997). Skeletal muscle fibre type transformation following spinal cord injury. Spinal Cord. 35, 86-91.

72. Martin, T.P., Stein, R.B., Hoeppner, P.H., and Reid, D.C. (1992). Influence of electrical stimulation on the morphological and metabolic properties of paralyzed muscle. J. Appl. Physiol. 72, 1401-1406.

73. Chilibeck, P.D., Jeon, J., Weiss, C., Bell, G., and Burnham, R. (1999). Histochemical changes in muscle of individuals with spinal cord injury following functional electrical stimulated exercise training. Spinal Cord 37, 264-268.

74. Gordon, T. and Mao, J. (1994). Muscle atrophy and procedures for training after spinal cord injury. Phys Ther 74, 50-60.

75. Shields, R.K. (2002). Muscular, skeletal, and neural adaptations following spinal cord injury. J. Orthop. Sports Phys. Ther. 32, 65-74.

76. Stein, R.B., Gordon, T., Jefferson, J., Sharfenberger, A., Yang, J.F., de Zepetnek, J.T., and Belanger, M. (1992). Optimal stimulation of paralyzed muscle after human spinal cord injury. J. Appl. Physiol. (1985) 72, 1393-1400.

77. Peckham, P.H., Mortimer, J.T., and Marsolais, E.B. (1976). Alteration in the force and fatigability of skeletal muscle in quadriplegic 
humans following exercise induced by chronic electrical stimulation. Clin Orthop. Relat. Res. 114, 326-334.

78. Gorgey, A.S. and Dudley, G.A. (2008). Spasticity may defend skeletal muscle size and composition after incomplete spinal cord injury. Spinal Cord 46, 96-102.

79. Lieber, R.L., Steinman, S., Barash, I.A., and Chambers, H. (2004). Structural and functional changes in spastic skeletal muscle. Muscle Nerve 29, 615-627.

80. Roy, R.R., Talmadge, R.J., Hodgson, J.A., Zhong, H., Baldwin, K.M., and Edgerton, V.R. (1998). Training effects on soleus of cats spinal cord transected (T12-13) as adults. Muscle Nerve 21, 63-71.

81. Roy, R.R. and Acosta, L. (1986). Fiber type and fiber size changes in selected thigh muscles six months after low thoracic spinal cord transection in adult cats: exercise effects. Exp. Neurol. 92, 675685.

82. Giszter, S.F., Hockensmith, G., Ramakrishnan, A., and Udoekwere, U.I. (2010). How spinalized rats can walk: biomechanics, cortex, and hindlimb muscle scaling-implications for rehabilitation. Ann. N. Y. Acad. Sci. 1198, 279-293.

83. Stewart, B.G., Tarnopolsky, M.A., Hicks, A.L., McCartney, N., Mahoney, D.J., Staron, R.S., and Phillips, S.M. (2004). Treadmill training-induced adaptations in muscle phenotype in persons with incomplete spinal cord injury. Muscle Nerve 30, 61-68.

84. Giangregorio, L.M., Webber, C.E., Phillips, S.M., Hicks, A.L., Craven, B.C., Bugaresti, J.M., and McCartney, N. (2006). Can body weight supported treadmill training increase bone mass and reverse muscle atrophy in individuals with chronic incomplete spinal cord injury? Appl. Physiol. Nutr. Metab. 31, 283-291.

85. Dietz, V. and Muller, R. (2004). Degradation of neuronal function following a spinal cord injury: mechanisms and countermeasures. Brain 127, 2221-2231.

86. Bennett, D.J., Hultborn, H., Fedirchuk, B., and Gorassini, M. (1998). Synaptic activation of plateaus in hindlimb motoneurons of decerebrate cats. J. Neurophysiol. 80, 2023-2037.

87. Hamm, T.M., Turkin, V.V., Bandekar, N.K., O’Neill, D., and Jung, R. (2010). Persistent currents and discharge patterns in rat hindlimb motoneurons. J. Neurophysiol. 104, 1566-1577.

88. Rekling, J.C., Funk, G.D., Bayliss, D.A., Dong, X.W., and Feldman, J.L. (2000). Synaptic control of motoneuronal excitability. Physiol. Rev. 80, 767-852.

89. Krawitz, S., Fedirchuk, B., Dai, Y., Jordan, L.M., and McCrea, D.A. (2001). State-dependent hyperpolarization of voltage threshold enhances motoneurone excitability during fictive locomotion in the cat. J. Physiol. 532, 271-281.

90. Powers, R.K. and Binder, M.D. (2001). Input-output functions of mammalian motoneurons. Rev. Physiol. Biochem. Pharmacol. 143, 137-263.

91. Heckman, C.J., Lee, R.H., and Brownstone, R.M. (2003). Hyperexcitable dendrites in motoneurons and their neuromodulatory control during motor behavior. Trends Neurosci. 26, 688-695.

92. Hultborn, H., Brownstone, R.B., Toth, T.I., and Gossard, J.P. (2004). Key mechanisms for setting the input-output gain across the motoneuron pool. Prog. Brain Res. 143, 77-95.

93. Harvey, P.J., Li, X., Li, Y., and Bennett, D.J. (2006). 5-HT2 receptor activation facilitates a persistent sodium current and repetitive firing in spinal motoneurons of rats with and without chronic spinal cord injury. J. Neurophysiol. 96, 1158-1170.

94. Li, X., Murray, K., Harvey, P.J., Ballou, E.W., and Bennett, D.J. (2007). Serotonin facilitates a persistent calcium current in motoneurons of rats with and without chronic spinal cord injury. J. Neurophysiol. 97, 1236-1246.

95. Hounsgaard, J., Hultborn, H., Jespersen, B., and Kiehn, O. (1988). Bistability of alpha-motoneurones in the decerebrate cat and in the acute spinal cat after intravenous 5-hydroxytryptophan. J. Physiol. 405, 345-367.

96. Murray, K.C., Nakae, A., Stephens, M.J., Rank, M., D’Amico, J., Harvey, P.J., Li, X., Harris, R.L., Ballou, E.W., Anelli, R., Heckman, C.J., Mashimo, T., Vavrek, R., Sanelli, L., Gorassini, M.A., Bennett, D.J., and Fouad, K. (2010). Recovery of motoneuron and locomotor function after spinal cord injury depends on constitutive activity in 5HT2C receptors. Nat. Med. 16, 694-700.

97. Bennett, D.J., Li, Y., and Siu, M. (2001). Plateau potentials in sacrocaudal motoneurons of chronic spinal rats, recorded in vitro. J. Neurophysiol. 86, 1955-1971.
98. Bennett, D.J., Li, Y., Harvey, P.J., and Gorassini, M. (2001). Evidence for plateau potentials in tail motoneurons of awake chronic spinal rats with spasticity. J. Neurophysiol. 86, 1972-1982.

99. Bennett, D.J., Gorassini, M., Fouad, K., Sanelli, L., Han, Y., and Cheng, J. (1999). Spasticity in rats with sacral spinal cord injury. J. Neurotrauma 16, 69-84.

100. Gorassini, M.A., Knash, M.E., Harvey, P.J., Bennett, D.J., and Yang, J.F. (2004). Role of motoneurons in the generation of muscle spasms after spinal cord injury. Brain 127, 2247-2258.

101. Norton, J.A., Bennett, D.J., Knash, M.E., Murray, K.C., and Gorassini, M.A. (2008). Changes in sensory-evoked synaptic activation of motoneurons after spinal cord injury in man. Brain 131, 1478-1491.

102. Johnson, M.D., Kajtaz, E., Cain, C.M., and Heckman, C.J. (2013). Motoneuron intrinsic properties, but not their receptive fields, recover in chronic spinal injury. J. Neurosci. 33, 18806-18813.

103. Hyngstrom, A., Johnson, M., Schuster, J., and Heckman, C.J. (2008) Movement-related receptive fields of spinal motoneurones with active dendrites. J. Physiol. 586, 1581-1593.

104. Eaton, M. (2003). Common animal models for spasticity and pain. J. Rehabil. Res. Dev. 40, 41-54.

105. Bouhadfane, M., Tazerart, S., Moqrich, A., Vinay, L., and Brocard, F. (2013). Sodium-mediated plateau potentials in lumbar motoneurons of neonatal rats. J. Neurosci. 33, 15626-15641.

106. Brocard, C., Plantier, V., Boulenguez, P., Liabeuf, S., Bouhadfane, M., Viallat-Lieutaud, A., Vinay, L., and Brocard, F. (2016). Cleavage of $\mathrm{Na}(+)$ channels by calpain increases persistent $\mathrm{Na}(+)$ current and promotes spasticity after spinal cord injury. Nat. Med. 22, 404-411.

107. Hunanyan, A.S., Alessi, V., Patel, S., Pearse, D.D., Matthews, G., and Arvanian, V.L. (2011). Alterations of action potentials and the localization of Nav1.6 sodium channels in spared axons after hemisection injury of the spinal cord in adult rats. J. Neurophysiol. 105, 1033-1044.

108. Woodrow, L., Sheppard, P, Gardiner, K.R., and Gardiner, P.F. (2010) Endurance exercise alters spinal motoneuron mRNA levels: mechanisms for enhanced excitability. Physiol. Nutr. Metab. 35, S1-S116.

109. Cormery, B., Marini, J.F., and Gardiner, P.F. (2000). Changes in electrophysiological properties of tibial motoneurones in the rat following 4 weeks of tetrodotoxin-induced paralysis. Neurosci. Lett. 287, 21-24.

110. Cormery, B., Beaumont, E., Csukly, K., and Gardiner, P. (2005) Hindlimb unweighting for 2 weeks alters physiological properties of rat hindlimb motoneurones. J. Physiol. 568, 841-850.

111. Cope, T.C., Bodine, S.C., Fournier, M., and Edgerton, V.R. (1986) Soleus motor units in chronic spinal transected cats: physiological and morphological alterations. J. Neurophysiol. 55, 1202-1220.

112. Munson, J.B., Foehring, R.C., Lofton, S.A., Zengel, J.E., and Sypert, G.W. (1986). Plasticity of medial gastrocnemius motor units following cordotomy in the cat. J. Neurophysiol. 55, 619-634.

113. Mayer, R.F., Burke, R.E., Toop, J., Walmsley, B., and Hodgson, J.A. (1984). The effect of spinal cord transection on motor units in cat medial gastrocnemius muscles. Muscle Nerve 7, 23-31.

114. Baker, L.L. and Chandler, S.H. (1987). Characterization of hindlimb motoneuron membrane properties in acute and chronic spinal cats. Brain Res. 420, 333-339.

115. Hochman, S. and McCrea, D.A. (1994). Effects of chronic spinalization on ankle extensor motoneurons. II. Motoneuron electrical properties. J. Neurophysiol. 71, 1468-1479.

116. Czeh, G., Gallego, R., Kudo, N., and Kuno, M. (1978). Evidence for the maintenance of motoneurone properties by muscle activity. J. Physiol. 281, 239-252.

117. Button, D.C., Kalmar, J.M., Gardiner, K., Marqueste, T., Zhong, H., Roy, R.R., Edgerton, V.R., and Gardiner, P.F. (2008). Does elimination of afferent input modify the changes in rat motoneurone properties that occur following chronic spinal cord transection? J. Physiol. 586, 529-544.

118. Beaumont, E., Houle, J.D., Peterson, C.A., and Gardiner, P.F. (2004). Passive exercise and fetal spinal cord transplant both help to restore motoneuronal properties after spinal cord transection in rats. Muscle Nerve 29, 234-242.

119. Petruska, J.C., Ichiyama, R.M., Jindrich, D.L., Crown, E.D., Tansey, K.E., Roy, R.R., Edgerton, V.R., and Mendell, L.M. (2007). Changes in motoneuron properties and synaptic inputs related to step training after spinal cord transection in rats. J. Neurosci. 27, 4460-4471.

120. Beaumont, E., Kaloustian, S., Rousseau, G., and Cormery, B. (2008). Training improves the electrophysiological properties of lumbar 
neurons and locomotion after thoracic spinal cord injury in rats Neurosci. Res. 62, 147-154.

121. Jordan, L.M. (1998). Initiation of locomotion in mammals. Ann.N.Y.Acad.Sci. 860, 83-93.

122. Reed, W.R., Shum-Siu, A., Onifer, S.M., and Magnuson, D.S. (2006). Inter-enlargement pathways in the ventrolateral funiculus of the adult rat spinal cord. Neuroscience 142, 1195-1207.

123. Reed, W.R., Shum-Siu, A., and Magnuson, D.S. (2008). Reticulospinal pathways in the ventrolateral funiculus with terminations in the cervical and lumbar enlargements of the adult rat spinal cord. Neuroscience 151, 505-517.

124. Reed, W.R., Shum-Siu, A., Whelan, A., Onifer, S.M., and Magnuson, D.S. (2009). Anterograde labeling of ventrolateral funiculus pathways with spinal enlargement connections in the adult rat spinal cord. Brain Res. 1302, 76-84.

125. Behrman, A.L. and Harkema, S.J. (2000). Locomotor training after human spinal cord injury: a series of case studies. Phys. Ther. 80, 688700 .

126. Kawashima, N., Nozaki, D., Abe, M.O., and Nakazawa, K. (2008). Shaping appropriate locomotive motor output through interlimb neural pathway within spinal cord in humans. J. Neurophysiol. 99, 2946-2955.

127. Goulding, M. (2009). Circuits controlling vertebrate locomotion: moving in a new direction. Nat. Rev. Neurosci. 10, 507-518.

128. Grillner, S. and Jessell, T.M. (2009). Measured motion: searching for simplicity in spinal locomotor networks. Curr. Opin. Neurobiol. 19 $572-586$.

129. Kiehn, O. (2016). Decoding the organization of spinal circuits that control locomotion. Nat. Rev. Neurosci. 17, 224-238.

130. Rybak, I.A., Dougherty, K.J., and Shevtsova, N.A. (2015). Organization of the mammalian locomotor CPG: review of computational model and circuit architectures based on renetically identified spinal interneurons $(1,2,3)$. eNeuro 2.

131. Gosgnach, S. (2011). The role of genetically-defined interneurons in generating the mammalian locomotor rhythm. Integr. Comp. Biol. 51, 903-912.

132. Kiehn, O., Johnson, B.R., and Raastad, M. (1996). Plateau properties in mammalian spinal interneurons during transmitter-induced locomotor activity. Neuroscience 75, 263-273.

133. Duysens, J. and Van de Crommert, H.W. (1998). Neural control of locomotion: the central pattern generator from cats to humans. Gait Posture. 7, 131-141.

134. Flynn, J.R., Graham, B.A., Galea, M.P., and Callister, R.J. (2011) The role of propriospinal interneurons in recovery from spinal cord injury. Neuropharmacology 60, 809-822.

135. Gossard, J.P., Delivet-Mongrain, H., Martinez, M., Kundu, A., Escalona, M., and Rossignol, S. (2015). Plastic changes in lumbar locomotor networks after a partial spinal cord injury in Cats. J. Neurosci. 35, 9446-9455.

136. Martinez, M., Delivet-Mongrain, H., Leblond, H., and Rossignol, S. (2012). Effect of locomotor training in completely spinalized cats previously submitted to a spinal hemisection. J. Neurosci. 32, 1096110970

137. Barriere, G., Leblond, H., Provencher, J., and Rossignol, S. (2008). Prominent role of the spinal central pattern generator in the recovery of locomotion after partial spinal cord injuries. J. Neurosci. 28, 3976-3987.

138. Flynn, J.R., Dunn, L.R., Galea, M.P., Callister, R., Callister, R.J., and Rank, M.M. (2013). Exercise training after spinal cord injury selectively alters synaptic properties in neurons in adult mouse spinal cord. J. Neurotrauma 30, 891-896.

139. Rank, M.M., Flynn, J.R., Battistuzzo, C.R., Galea, M.P., Callister, R., and Callister, R.J. (2015). Functional changes in deep dorsal horn interneurons following spinal cord injury are enhanced with different durations of exercise training. J. Physiol. 593, 331-345.

140. Husch, A., Van Patten, G.N., Hong, D.N., Scaperotti, M.M., Cramer, N., and Harris-Warrick, R.M. (2012). Spinal cord injury induces serotonin supersensitivity without increasing intrinsic excitability of mouse V2a interneurons. J. Neurosci. 32, 13145-13154.

141. Kapitza, S., Zorner, B., Weinmann, O., Bolliger, M., Filli, L., Dietz, V., and Schwab, M.E. (2012). Tail spasms in rat spinal cord injury: changes in interneuronal connectivity. Exp. Neurol. 236, 179-189.

142. Huang, A., Noga, B.R., Carr, P.A., Fedirchuk, B., and Jordan, L.M (2000). Spinal cholinergic neurons activated during locomotion: localization and electrophysiological characterization. J. Neurophysiol. 83, 3537-3547.
143. Zagoraiou, L., Akay, T., Martin, J.F., Brownstone, R.M., Jessell, T.M., and Miles, G.B. (2009). A cluster of cholinergic premotor interneurons modulates mouse locomotor activity. Neuron 64, 645662.

144. Bareyre, F.M., Kerschensteiner, M., Raineteau, O., Mettenleiter, T.C., Weinmann, O., and Schwab, M.E. (2004). The injured spinal cord spontaneously forms a new intraspinal circuit in adult rats. Nat. Neurosci. 7, 269-277.

145. Courtine, G., Song, B., Roy, R.R., Zhong, H., Herrmann, J.E., Ao, Y., Qi, J., Edgerton, V.R., and Sofroniew, M.V. (2008). Recovery of supraspinal control of stepping via indirect propriospinal relay connections after spinal cord injury. Nat. Med. 14, 69-74.

146. Filli, L., Engmann, A.K., Zorner, B., Weinmann, O., Moraitis, T., Gullo, M., Kasper, H., Schneider, R., and Schwab, M.E. (2014). Bridging the gap: a reticulo-propriospinal detour bypassing an incomplete spinal cord injury. J. Neurosci. 34, 13399-13410.

147. van den Brand, R., Heutschi, J., Barraud, Q., DiGiovanna, J., Bartholdi, K., Huerlimann, M., Friedli, L., Vollenweider, I., Moraud, E.M., Duis, S., Dominici, N., Micera, S., Musienko, P., and Courtine, G. (2012). Restoring voluntary control of locomotion after paralyzing spinal cord injury. Science 336, 1182-1185.

148. Hollis, E.R., 2nd, Ishiko, N., Pessian, M., Tolentino, K., Lee-Kubli, C.A., Calcutt, N.A., and Zou, Y. (2015). Remodelling of spared proprioceptive circuit involving a small number of neurons supports functional recovery. Nat. Commun. 6, 6079.

149. Siebert, J.R., Middleton, F.A., and Stelzner, D.J. (2010). Long descending cervical propriospinal neurons differ from thoracic propriospinal neurons in response to low thoracic spinal injury. BMC Neurosci. 11, 148.

150. Siebert, J.R., Middelton, F.A., and Stelzner, D.J. (2010). Intrinsic response of thoracic propriospinal neurons to axotomy. BMC Neurosci. 11,69 .

151. Deng, L.X., Deng, P., Ruan, Y., Xu, Z.C., Liu, N.K., Wen, X., Smith, G.M., and Xu, X.M. (2013). A novel growth-promoting pathway formed by GDNF-overexpressing Schwann cells promotes propriospinal axonal regeneration, synapse formation, and partial recovery of function after spinal cord injury. J. Neurosci. 33, 5655-5667.

152. Sachdeva, R., Theisen, C.C., Ninan, V., Twiss, J.L., and Houle, J.D (2016). Exercise dependent increase in axon regeneration into peripheral nerve grafts by propriospinal but not sensory neurons after spinal cord injury is associated with modulation of regenerationassociated genes. Exp. Neurol. 276, 72-82.

153. Pearson, K.G. (1995). Proprioceptive regulation of locomotion. Curr. Opin. Neurobiol. 5, 786-791.

154. Markin, S.N., Klishko, A.N., Shevtsova, N.A., Lemay, M.A., Prilutsky, B.I., and Rybak, I.A. (2010). Afferent control of locomotor CPG: insights from a simple neuromechanical model. Ann. N. Y. Acad. Sci. 1198, 21-34.

155. Panek, I., Bui, T., Wright, A.T., and Brownstone, R.M. (2014). Cutaneous afferent regulation of motor function. Acta Neurobiol. Exp. (Wars.) 74, 158-171.

156. Muir, G.D. and Steeves, J.D. (1995). Phasic cutaneous input facilitates locomotor recovery after incomplete spinal injury in the chick. J. Neurophysiol. 74, 358-368.

157. Muir, G.D. and Steeves, J.D. (1997). Sensorimotor stimulation to improve locomotor recovery after spinal cord injury. Trends Neurosci. 20, 72-77.

158. Smith, R.R., Shum-Siu, A., Baltzley, R., Bunger, M., Baldini, A., Burke, D.A., and Magnuson, D.S. (2006). Effects of swimming on functional recovery after incomplete spinal cord injury in rats. J. Neurotrauma 23, 908-919.

159. Bouyer, L.J. and Rossignol, S. (2003). Contribution of cutaneous inputs from the hindpaw to the control of locomotion. II. Spinal cats. J. Neurophysiol. 90, 3640-3653.

160. Knikou, M. (2010). Plantar cutaneous afferents normalize the reflex modulation patterns during stepping in chronic human spinal cord injury. J. Neurophysiol. 103, 1304-1314.

161. Knikou, M., Angeli, C.A., Ferreira, C.K., and Harkema, S.J. (2009) Soleus H-reflex modulation during body weight support treadmill walking in spinal cord intact and injured subjects. Exp. Brain Res 193, 397-407.

162. Knikou, M., Hajela, N., Mummidisetty, C.K., Xiao, M., and Smith, A.C. (2011). Soleus H-reflex phase-dependent modulation is preserved during stepping within a robotic exoskeleton. Clin. Neurophysiol. 122, 1396-1404. 
163. Knikou, M. (2013). Functional reorganization of soleus H-reflex modulation during stepping after robotic-assisted step training in people with complete and incomplete spinal cord injury. Exp. Brain Res. 228, 279-296.

164. Smith, A.C., Mummidisetty, C.K., Rymer, W.Z., and Knikou, M. (2014). Locomotor training alters the behavior of flexor reflexes during walking in human spinal cord injury. J. Neurophysiol. 112, 2164-2175.

165. Knikou, M., Smith, A.C., and Mummidisetty, C.K. (2015). Locomotor training improves reciprocal and nonreciprocal inhibitory control of soleus motoneurons in human spinal cord injury. J. Neurophysiol. 113, 2447-2460.

166. Stephens, M.J. and Yang, J.F. (1996). Short latency, non-reciprocal group I inhibition is reduced during the stance phase of walking in humans. Brain Res. 743, 24-31.

167. Duysens, J. and Pearson, K.G. (1980). Inhibition of flexor burst generation by loading ankle extensor muscles in walking cats. Brain Res. 187, 321-332.

168. McCrea, D.A., Shefchyk, S.J., Stephens, M.J., and Pearson, K.G. (1995). Disynaptic group I excitation of synergist ankle extensor motoneurones during fictive locomotion in the cat. J. Physiol. 487 ( Pt 2), 527-539.

169. Bolliger, M., Trepp, A., Zorner, B., and Dietz, V. (2010). Modulation of spinal reflex by assisted locomotion in humans with chronic complete spinal cord injury. Clin. Neurophysiol. 121, 2152-2158.

170. Malmsten, J. (1983). Time course of segmental reflex changes after chronic spinal cord hemisection in the rat. Acta Physiol. Scand. 119, 435-443.

171. Valero-Cabre, A., Fores, J., and Navarro, X. (2004). Reorganization of reflex responses mediated by different afferent sensory fibres after spinal cord transection. J. Neurophysiol. 91, 2838-2848.

172. Frigon, A. and Rossignol, S. (2008). Adaptive changes of the locomotor pattern and cutaneous reflexes during locomotion studied in the same cats before and after spinalization. J. Physiol. 586, 2927-2945.

173. Frigon, A. and Rossignol, S. (2009). Partial denervation of ankle extensors prior to spinalization in cats impacts the expression of locomotion and the phasic modulation of reflexes. Neuroscience 158, 1675-1690.

174. Frigon, A., Barriere, G., Leblond, H., and Rossignol, S. (2009). Asymmetric changes in cutaneous reflexes after a partial spinal lesion and retention following spinalization during locomotion in the cat. J. Neurophysiol. 102, 2667-2680.

175. Frigon, A., Johnson, M.D., and Heckman, C.J. (2011). Altered activation patterns by triceps surae stretch reflex pathways in acute and chronic spinal cord injury. J. Neurophysiol. 106, 1669-1678.

176. Gorassini, M.A., Norton, J.A., Nevett-Duchcherer, J., Roy, F.D., and Yang, J.F. (2009). Changes in locomotor muscle activity after treadmill training in subjects with incomplete spinal cord injury. J. Neurophysiol. 101, 969-979.

177. Meyns, P., Van de Crommert, H.W., Rijken, H., van Kuppevelt, D.H., and Duysens, J. (2014). Locomotor training with body weight support in SCI: EMG improvement is more optimally expressed at a low testing speed. Spinal Cord 52, 887-893.

178. Yang, J.F., Norton, J., Nevett-Duchcherer, J., Roy, F.D., Gross, D.P., and Gorassini, M.A. (2011). Volitional muscle strength in the legs predicts changes in walking speed following locomotor training in people with chronic spinal cord injury. Phys. Ther. 91, 931-943.

179. Singh, A., Balasubramanian, S., Murray, M., Lemay, M., and Houle, J. (2011). Role of spared pathways in locomotor recovery after bodyweight-supported treadmill training in contused rats. J. Neurotrauma 28, 2405-2416.

180. Drew, T., Jiang, W., and Widajewicz, W. (2002). Contributions of the motor cortex to the control of the hindlimbs during locomotion in the cat. Brain Res. Brain Res. Rev. 40, 178-191.

181. Petersen, T.H., Willerslev-Olsen, M., Conway, B.A., and Nielsen, J.B. (2012). The motor cortex drives the muscles during walking in human subjects. J. Physiol. 590, 2443-2452.

182. Benito, J., Kumru, H., Murillo, N., Costa, U., Medina, J., Tormos, J.M., Pascual-Leone, A., and Vidal, J. (2012). Motor and gait improvement in patients with incomplete spinal cord injury induced by high-frequency repetitive transcranial magnetic stimulation. Top. Spinal Cord Inj. Rehabil. 18, 106-112.

183. Hofstoetter, U.S., Krenn, M., Danner, S.M., Hofer, C., Kern, H., McKay, W.B., Mayr, W., and Minassian, K. (2015). Augmentation of voluntary locomotor activity by transcutaneous spinal cord stimulation in motor-incomplete spinal cord-injured individuals. Artif. Organs 39, E176-E186.
184. Knikou, M. (2014). Transpinal and transcortical stimulation alter corticospinal excitability and increase spinal output. PLoS One 9, e102313.

185. Manella, K.J., Roach, K.E., and Field-Fote, E.C. (2013). Operant conditioning to increase ankle control or decrease reflex excitability improves reflex modulation and walking function in chronic spinal cord injury. J. Neurophysiol. 109, 2666-2679.

186. Tansey, K.E. (2010). Neural plasticity and locomotor recovery after spinal cord injury. PM R 2, S220-226.

187. Buehner, J.J., Forrest, G.F., Schmidt-Read, M., White, S., Tansey, K., and Basso, D.M. (2012). Relationship between ASIA examination and functional outcomes in the NeuroRecovery Network Locomotor Training Program. Arch. Phys. Med. Rehabil. 93, 1530-1540.

188. Winchester, P., McColl, R., Querry, R., Foreman, N., Mosby, J., Tansey, K., and Williamson, J. (2005). Changes in supraspinal activation patterns following robotic locomotor therapy in motor-incomplete spinal cord injury. Neurorehabil. Neural Repair 19, 313-324.

189. Barthelemy, D., Willerslev-Olsen, M., Lundell, H., BieringSorensen, F., and Nielsen, J.B. (2015). Assessment of transmission in specific descending pathways in relation to gait and balance following spinal cord injury. Prog. Brain Res. 218, 79-101.

190. Eidelberg, E. (1981). Consequences of spinal cord lesions upon motor function, with special reference to locomotor activity. Prog. Neurobiol. 17, 185-202.

191. Jiang, W. and Drew, T. (1996). Effects of bilateral lesions of the dorsolateral funiculi and dorsal columns at the level of the low thoracic spinal cord on the control of locomotion in the adult cat. I. Treadmill walking. J. Neurophysiol. 76, 849-866.

192. Lawrence, D.G. and Kuypers, H.G. (1968). The functional organization of the motor system in the monkey. I. The effects of bilateral pyramidal lesions. Brain 91, 1-14.

193. Bucy, P.C., Ladpli, R., and Ehrlich, A. (1966). Destruction of the pyramidal tract in the monkey. The effects of bilateral section of the cerebral peduncles. J. Neurosurg. 25, 1-23.

194. Eidelberg, E., Walden, J.G., and Nguyen, L.H. (1981). Locomotor control in macaque monkeys. Brain 104, 647-663.

195. Nathan, P.W. (1994). Effects on movement of surgical incisions into the human spinal cord. Brain 117 ( Pt 2), 337-346.

196. Brustein, E. and Rossignol, S. (1998). Recovery of locomotion after ventral and ventrolateral spinal lesions in the cat. I. Deficits and adaptive mechanisms. J. Neurophysiol. 80, 1245-1267.

197. Bem, T., Gorska, T., Majczynski, H., and Zmyslowski, W. (1995). Different patterns of fore-hindlimb coordination during overground locomotion in cats with ventral and lateral spinal lesions. Exp. Brain Res. 104, 70-80.

198. Gorska, T., Bem, T., Majczynski, H., and Zmyslowski, W. (1993) Unrestrained walking in cats with partial spinal lesions. Brain Res. Bull. 32, 241-249.

199. Gorska, T., Majczynski, H., Bem, T., and Zmyslowski, W. (1993). Hindlimb swing, stance and step relationships during unrestrained walking in cats with lateral funicular lesion. Acta Neurobiol. Exp. (Wars) 53, 133-142.

200. Lawrence, D.G. and Kuypers, H.G. (1968). The functional organization of the motor system in the monkey. II. The effects of lesions of the descending brain-stem pathways. Brain 91, 15-36.

201. Zewdie, E.T., Roy, F.D., Yang, J.F., and Gorassini, M.A. (2015) Facilitation of descending excitatory and spinal inhibitory networks from training of endurance and precision walking in participants with incomplete spinal cord injury. Prog. Brain Res. 218, 127-155.

202. Minassian, K. and Hofstoetter, U.S. (2016). Spinal Cord Stimulation and Augmentative Control Strategies for Leg Movement after Spinal Paralysis in Humans. CNS Neurosci. Ther. 22, 262-270.

203. Minassian, K., Hofstoetter, U.S., Danner, S.M., Mayr, W., Bruce, J.A., McKay, W.B., and Tansey, K.E. (2016). Spinal rhythm generation by step-induced feedback and transcutaneous posterior root stimulation in complete spinal cord-injured individuals. Neurorehabil. Neural Repair 30, 233-243.

204. Angeli, C.A., Edgerton, V.R., Gerasimenko, Y.P., and Harkema, S.J (2014). Altering spinal cord excitability enables voluntary movements after chronic complete paralysis in humans. Brain 137, 1394-1409.

205. Edgerton, V.R. and Harkema, S. (2011). Epidural stimulation of the spinal cord in spinal cord injury: current status and future challenges. Expert Rev. Neurother. 11, 1351-1353.

206. Goldshmit, Y., Lythgo, N., Galea, M.P., and Turnley, A.M. (2008). Treadmill training after spinal cord hemisection in mice promotes 
axonal sprouting and synapse formation and improves motor recovery. J. Neurotrauma 25, 449-465.

207. Carmel, J.B., Kimura, H., Berrol, L.J., and Martin, J.H. (2013). Motor cortex electrical stimulation promotes axon outgrowth to brain stem and spinal targets that control the forelimb impaired by unilateral corticospinal injury. Eur. J. Neurosci. 37, 1090-1102.

208. Jiang, Y.Q., Zaaimi, B., and Martin, J.H. (2016). Competition with primary sensory afferents drives remodeling of corticospinal axons in mature spinal motor circuits. J. Neurosci. 36, 193-203.

209. Carmel, J.B., Kimura, H., and Martin, J.H. (2014). Electrical stimulation of motor cortex in the uninjured hemisphere after chronic unilateral injury promotes recovery of skilled locomotion through ipsilateral control. J. Neurosci. 34, 462-466.

210. Carmel, J.B. and Martin, J.H. (2014). Motor cortex electrical stimulation augments sprouting of the corticospinal tract and promotes recovery of motor function. Front. Integr. Neurosci. 8, 51.

211. Martin, J.H., Kably, B., and Hacking, A. (1999). Activity-dependent development of cortical axon terminations in the spinal cord and brain stem. Exp. Brain Res. 125, 184-199.

212. Vavrek, R., Pearse, D.D., and Fouad, K. (2007). Neuronal populations capable of regeneration following a combined treatment in rats with spinal cord transection. J. Neurotrauma 24, 1667-1673.

213. Kubasak, M.D., Jindrich, D.L., Zhong, H., Takeoka, A., McFarland, K.C., Munoz-Quiles, C., Roy, R.R., Edgerton, V.R., Ramon-Cueto, A., and Phelps, P.E. (2008). OEG implantation and step training enhance hindlimb-stepping ability in adult spinal transected rats. Brain 131, 264-276.

214. Munoz-Quiles, C., Santos-Benito, F.F., Llamusi, M.B., and RamonCueto, A. (2009). Chronic spinal injury repair by olfactory bulb ensheathing glia and feasibility for autologous therapy. J. Neuropathol. Exp. Neurol. 68, 1294-1308.

215. Takeoka, A., Jindrich, D.L., Munoz-Quiles, C., Zhong, H., van den, B.R., Pham, D.L., Ziegler, M.D., Ramon-Cueto, A., Roy, R.R., Edgerton, V.R., and Phelps, P.E. (2011). Axon regeneration can facilitate or suppress hindlimb function after olfactory ensheathing glia transplantation. J. Neurosci. 31, 4298-4310.

216. Lee, Y.S., Zdunowski, S., Edgerton, V.R., Roy, R.R., Zhong, H., Hsiao, I., and Lin, V.W. (2010). Improvement of gait patterns in step-trained, complete spinal cord-transected rats treated with a peripheral nerve graft and acidic fibroblast growth factor. Exp. Neurol. 224, 429-437.

217. Goldberger, M.E. and Murray, M. (1978). Recovery of movement and axonal sprouting may obey some of the same laws. In: Neuronal Plasticity. Cotman, C.W. (ed). Raven Press: New York, pps. 73-96.

218. Rossignol, S. and Frigon, A. (2011). Recovery of locomotion after spinal cord injury: some facts and mechanisms. Annu. Rev. Neurosci. 34, 413-440.

219. Ichiyama, R.M., Broman, J., Roy, R.R., Zhong, H., Edgerton, V.R., and Havton, L.A. (2011). Locomotor training maintains normal inhibitory influence on both alpha- and gamma-motoneurons after neonatal spinal cord transection. J. Neurosci. 31, 26-33.

220. Macias, M., Nowicka, D., Czupryn, A., Sulejczak, D., Skup, M., Skangiel-Kramska, J., and Czarkowska-Bauch, J. (2009). Exerciseinduced motor improvement after complete spinal cord transection and its relation to expression of brain-derived neurotrophic factor and presynaptic markers. BMC Neurosci. 10, 144.

221. Skup, M., Gajewska-Wozniak, O., Grygielewicz, P., Mankovskaya, T., and Czarkowska-Bauch, J. (2012). Different effects of spinalization and locomotor training of spinal animals on cholinergic innervation of the soleus and tibialis anterior motoneurons. Eur. J. Neurosci. 36, 2679-2688.

222. Khristy, W., Ali, N.J., Bravo, A.B., de, L.R., Roy, R.R., Zhong, H., London, N.J., Edgerton, V.R., and Tillakaratne, N.J. (2009). Changes in $\mathrm{GABA}(\mathrm{A})$ receptor subunit gamma 2 in extensor and flexor motoneurons and astrocytes after spinal cord transection and motor training. Brain Res. 1273, 9-17.

223. Perrier, J.F., Rasmussen, H.B., Christensen, R.K., and Petersen, A.V. (2013). Modulation of the intrinsic properties of motoneurons by serotonin. Curr. Pharm. Des. 19, 4371-4384.

224. Gerin, C., Becquet, D., and Privat, A. (1995). Direct evidence for the link between monoaminergic descending pathways and motor activity. I. A study with microdialysis probes implanted in the ventral funiculus of the spinal cord. Brain Res. 704, 191-201.

225. Noga, B.R., Johnson, D.M., Riesgo, M.I., and Pinzon, A. (2009). Locomotor-activated neurons of the cat. I. Serotonergic innervation and co-localization of 5-HT7, 5-HT2A, and 5-HT1A receptors in the thoraco-lumbar spinal cord. J. Neurophysiol. 102, 1560-1576.

226. Gimenez y Ribotta, M., Orsal, D., Feraboli-Lohnherr, D., and Privat, A. (1998). Recovery of locomotion following transplantation of monoaminergic neurons in the spinal cord of paraplegic rats. Ann. N. Y. Acad. Sci. 860, 393-411.

227. Ribotta, M.G., Provencher, J., Feraboli-Lohnherr, D., Rossignol, S., Privat, A., and Orsal, D. (2000). Activation of locomotion in adult chronic spinal rats is achieved by transplantation of embryonic raphe cells reinnervating a precise lumbar level. J. Neurosci. 20, 51445152.

228. Feraboli-Lohnherr, D., Barthe, J.Y., and Orsal, D. (1999). Serotonininduced activation of the network for locomotion in adult spinal rats. J. Neurosci. Res. 55, 87-98.

229. Antri, M., Mouffle, C., Orsal, D., and Barthe, J.Y. (2003). 5-HT1A receptors are involved in short- and long-term processes responsible for 5-HT-induced locomotor function recovery in chronic spinal rat. Eur. J. Neurosci. 18, 1963-1972.

230. Antri, M., Barthe, J.Y., Mouffle, C., and Orsal, D. (2005). Long-lasting recovery of locomotor function in chronic spinal rat following chronic combined pharmacological stimulation of serotonergic receptors with 8OHDPAT and quipazine. Neurosci. Lett. 384, 162-167.

231. Slawinska, U., Miazga, K., Cabaj, A.M., Leszczynska, A.N., Majczynski, H., Nagy, J.I., and Jordan, L.M. (2013). Grafting of fetal brainstem 5-HT neurons into the sublesional spinal cord of paraplegic rats restores coordinated hindlimb locomotion. Exp. Neurol. 247, 572-581.

232. Slawinska, U., Miazga, K., and Jordan, L.M. (2014). 5-HT(2) and 5HT(7) receptor agonists facilitate plantar stepping in chronic spinal rats through actions on different populations of spinal neurons. Front. Neural Circuits 8, 95

233. Barbeau, H. and Rossignol, S. (1990). The effects of serotonergic drugs on the locomotor pattern and on cutaneous reflexes of the adult chronic spinal cat. Brain Res. 514, 55-67.

234. Brustein, E. and Rossignol, S. (1999). Recovery of locomotion after ventral and ventrolateral spinal lesions in the cat. II. Effects of noradrenergic and serotoninergic drugs. J. Neurophysiol. 81, 1513-1530.

235. Gerasimenko, Y.P., Ichiyama, R.M., Lavrov, I.A., Courtine, G., Cai, L., Zhong, H., Roy, R.R., and Edgerton, V.R. (2007). Epidural spinal cord stimulation plus quipazine administration enable stepping in complete spinal adult rats. J. Neurophysiol. 98, 2525-2536.

236. Ichiyama, R.M., Gerasimenko, Y.P., Zhong, H., Roy, R.R., and Edgerton, V.R. (2005). Hindlimb stepping movements in complete spinal rats induced by epidural spinal cord stimulation. Neurosci. Lett. 383, 339344.

237. Engesser-Cesar, C., Ichiyama, R.M., Nefas, A.L., Hill, M.A., Edgerton, V.R., Cotman, C.W., and Anderson, A.J. (2007). Wheel running following spinal cord injury improves locomotor recovery and stimulates serotonergic fiber growth. Eur. J. Neurosci. 25, 1931-1939.

238. Perrin, F.E., Gerber, Y.N., Teigell, M., Lonjon, N., Boniface, G., Bauchet, L., Rodriguez, J.J., Hugnot, J.P., and Privat, A.M. (2011). Anatomical study of serotonergic innervation and 5-HT(1A) receptor in the human spinal cord. Cell Death Dis. 2, e218.

239. Gonzalez-Maeso, J. and Sealfon, S.C. (2009). Psychedelics and schizophrenia. Trends Neurosci. 32, 225-232.

240. Thompson, C.K. and Hornby, T.G. (2013). Divergent modulation of clinical measures of volitional and reflexive motor behaviors following serotonergic medications in human incomplete spinal cord injury. J. Neurotrauma 30, 498-502.

241. Leech, K.A., Kinnaird, C.R., and Hornby, T.G. (2014). Effects of serotonergic medications on locomotor performance in humans with incomplete spinal cord injury. J. Neurotrauma 31, 1334-1342.

242. Boyce, V.S. and Mendell, L.M. (2014). Neurotrophins and spinal circuit function. Front. Neural Circuits 8, 59.

243. English, A.W., Wilhelm, J.C., and Ward, P.J. (2014). Exercise, neurotrophins, and axon regeneration in the PNS. Physiology (Bethesda) 29, 437-445

244. Lopez-Alvarez, V.M., Modol, L., Navarro, X., and Cobianchi, S (2015). Early increasing-intensity treadmill exercise reduces neuropathic pain by preventing nociceptor collateral sprouting and disruption of chloride cotransporters homeostasis after peripheral nerve injury. Pain 156, 1812-1825.

245. Gomez-Pinilla, F., Ying, Z., Roy, R.R., Hodgson, J., and Edgerton, V.R. (2004). Afferent input modulates neurotrophins and synaptic plasticity in the spinal cord. J. Neurophysiol. 92, 3423-3432. 
246. Hutchinson, K.J., Gomez-Pinilla, F., Crowe, M.J., Ying, Z., and Basso, D.M. (2004). Three exercise paradigms differentially improve sensory recovery after spinal cord contusion in rats. Brain 127, 1403-1414.

247. Ferris, L.T., Williams, J.S., and Shen, C.L. (2007). The effect of acute exercise on serum brain-derived neurotrophic factor levels and cognitive function. Med. Sci. Sports Exerc. 39, 728-734.

248. Schmolesky, M.T., Webb, D.L., and Hansen, R.A. (2013). The effects of aerobic exercise intensity and duration on levels of brain-derived neurotrophic factor in healthy men. J. Sports. Sci. Med. 12, 502-511.

249. Ollivier-Lanvin, K., Fischer, I., Tom, V., Houle, J.D., and Lemay, M.A. (2015). Either brain-derived neurotrophic factor or neurotrophin-3 only neurotrophin-producing grafts promote locomotor recovery in untrained spinalized cats. Neurorehabil. Neural Repair 29, 90-100.

250. Jakeman, L.B., Wei, P., Guan, Z., and Stokes, B.T. (1998). Brainderived neurotrophic factor stimulates hindlimb stepping and sprouting of cholinergic fibers after spinal cord injury. Exp. Neurol. 154, 170-184.

251. Ziemlinska, E., Kugler, S., Schachner, M., Wewior, I., CzarkowskaBauch, J., and Skup, M. (2014). Overexpression of BDNF increases excitability of the lumbar spinal network and leads to robust early locomotor recovery in completely spinalized rats. PLoS One 9, e88833.

252. Boyce, V.S. and Mendell, L.M. (2014). Neurotrophic factors in spinal cord injury. Handb. Exp. Pharmacol. 220, 443-460.

253. Weishaupt, N., Blesch, A., and Fouad, K. (2012). BDNF: the career of a multifaceted neurotrophin in spinal cord injury. Exp. Neurol. 238, 254-264.

254. Xia, R. and Rymer, W.Z. (2005). Reflex reciprocal facilitation of antagonist muscles in spinal cord injury. Spinal Cord. 43, 14-21.

255. Boorman, G.I., Lee, R.G., Becker, W.J., and Windhorst, U.R. (1996). Impaired "natural reciprocal inhibition" in patients with spasticity due to incomplete spinal cord injury. Electroencephalogr. Clin. Neurophysiol. 101, 84-92.

256. Morita, H., Shindo, M., Momoi, H., Yanagawa, S., Ikeda, S., and Yanagisawa, N. (2006). Lack of modulation of Ib inhibition during antagonist contraction in spasticity. Neurology 67, 52-56.

257. Morita, H., Crone, C., Christenhuis, D., Petersen, N.T., and Nielsen, J.B. (2001). Modulation of presynaptic inhibition and disynaptic reciprocal Ia inhibition during voluntary movement in spasticity. Brain 124, 826-837.

258. Schindler-Ivens, S. and Shields, R.K. (2000). Low frequency depression of H-reflexes in humans with acute and chronic spinal-cord injury. Exp. Brain Res. 133, 233-241.

259. Faist, M., Mazevet, D., Dietz, V., and Pierrot-Deseilligny, E. (1994). A quantitative assessment of presynaptic inhibition of Ia afferents in spastics. Differences in hemiplegics and paraplegics. Brain $117(\mathrm{Pt}$ 6), 1449-1455.

260. Rossignol, S., Dubuc, R., and Gossard, J.P. (2006). Dynamic sensorimotor interactions in locomotion. Physiol. Rev. 86, 89-154.

261. Hart, B.L. (1971). Facilitation by strychnine of reflex walking in spinal dogs. Physiol. Behav. 6, 627-628.

262. Robinson, G.A. and Goldberger, M.E. (1986). The development and recovery of motor function in spinal cats. II. Pharmacological enhancement of recovery. Exp. Brain Res. 62, 387-400.

263. De Leon, R.D., Tamaki, H., Hodgson, J.A., Roy, R.R., and Edgerton, V.R. (1999). Hindlimb locomotor and postural training modulates glycinergic inhibition in the spinal cord of the adult spinal cat. J. Neurophysiol. 82, 359-369.

264. Edgerton, V.R., De Leon, R.D., Tillakaratne, N., Recktenwald, M.R., Hodgson, J.A., and Roy, R.R. (1997). Use-dependent plasticity in spinal stepping and standing. Adv. Neurol. 72, 233-247.

265. Tillakaratne, N.J., De Leon, R.D., Hoang, T.X., Roy, R.R., Edgerton, V.R., and Tobin, A.J. (2002). Use-dependent modulation of inhibitory capacity in the feline lumbar spinal cord. J. Neurosci. 22, 3130-3143.

266. Tillakaratne, N.J., Mouria, M., Ziv, N.B., Roy, R.R., Edgerton, V.R., and Tobin, A.J. (2000). Increased expression of glutamate decarboxylase $(\mathrm{GAD}(67))$ in feline lumbar spinal cord after complete thoracic spinal cord transection. J. Neurosci. Res. 60, 219-230.

267. Delpire, E. (2000). Cation-chloride cotransporters in neuronal communication. News Physiol Sci. 15, 309-312.
268. Payne, J.A., Rivera, C., Voipio, J., and Kaila, K. (2003). Cationchloride co-transporters in neuronal communication, development and trauma. Trends Neurosci. 26, 199-206.

269. Boulenguez, P., Liabeuf, S., Bos, R., Bras, H., Jean-Xavier, C., Brocard, C., Stil, A., Darbon, P., Cattaert, D., Delpire, E., Marsala, M., and Vinay, L. (2010). Down-regulation of the potassium-chloride cotransporter KCC2 contributes to spasticity after spinal cord injury. Nat. Med. 16, 302-307.

270. Cramer, S.W., Baggott, C., Cain, J., Tilghman, J., Allcock, B., Miranpuri, G., Rajpal, S., Sun, D., and Resnick, D. (2008). The role of cation-dependent chloride transporters in neuropathic pain following spinal cord injury. Mol. Pain 4, 36.

271. Lu, Y., Zheng, J., Xiong, L., Zimmermann, M., and Yang, J. (2008) Spinal cord injury-induced attenuation of GABAergic inhibition in spinal dorsal horn circuits is associated with down-regulation of the chloride transporter KCC2 in rat. J. Physiol 586, 5701-5715.

272. Bos, R., Sadlaoud, K., Boulenguez, P., Buttigieg, D., Liabeuf, S., Brocard, C., Haase, G., Bras, H., and Vinay, L. (2013). Activation of 5-HT2A receptors upregulates the function of the neuronal $\mathrm{K}-\mathrm{Cl}$ cotransporter KCC2. Proc. Natl. Acad. Sci. U. S. A. 110, 348-353.

273. Côté, M.-P., Gandhi, S., Zambrotta, M., and Houle, J.D. (2014). Exercise modulates chloride homeostasis after spinal cord injury. J. Neurosci. 34, 8976-8987.

274. Fiumelli, H. and Woodin, M.A. (2007). Role of activity-dependent regulation of neuronal chloride homeostasis in development. Curr. Opin. Neurobiol. 17, 81-86.

275. Rivera, C., Voipio, J., Thomas-Crusells, J., Li, H., Emri, Z., Sipila, S., Payne, J.A., Minichiello, L., Saarma, M., and Kaila, K. (2004). Mechanism of activity-dependent downregulation of the neuronspecific K-Cl cotransporter KCC2. J. Neurosci. 24, 4683-4691.

276. Rivera, C., Li, H., Thomas-Crusells, J., Lahtinen, H., Viitanen, T., Nanobashvili, A., Kokaia, Z., Airaksinen, M.S., Voipio, J., Kaila, K., and Saarma, M. (2002). BDNF-induced TrkB activation downregulates the $\mathrm{K}+-\mathrm{Cl}$ - cotransporter $\mathrm{KCC} 2$ and impairs neuronal $\mathrm{Cl}$ extrusion. J. Cell Biol. 159, 747-752.

277. Kaila, K., Lamsa, K., Smirnov, S., Taira, T., and Voipio, J. (1997) Long-lasting GABA-mediated depolarization evoked by highfrequency stimulation in pyramidal neurons of rat hippocampal slice is attributable to a network-driven, bicarbonate-dependent $\mathrm{K}+$ transient. J. Neurosci. 17, 7662-7672.

278. Fiumelli, H., Cancedda, L. and Poo, M.M. (2005). Modulation of GABAergic transmission by activity via postsynaptic $\mathrm{Ca} 2+$ dependent regulation of KCC2 function. Neuron 48, 773-786.

279. Côte, M.P. and Houle, J.D. (2013). Chloride cotransporter KCC2 is essential to exercise-dependent recovery of spinal reflexes after SCI. Presented at the Society for Neuroscience Conference, San Diego.

280. Tashiro, S., Shinozaki, M., Mukaino, M., Renault-Mihara, F., Toyama, Y., Liu, M., Nakamura, M., and Okano, H. (2015). BDNF induced by treadmill training contributes to the suppression of spasticity and allodynia after spinal cord injury via upregulation of KCC2. Neurorehabil. Neural Repair 29, 677-689.

281. Simon, O. and Yelnik, A.P. (2010). Managing spasticity with drugs. Eur. J. Phys. Rehabil. Med. 46, 401-410.

282. Lapeyre, E., Kuks, J.B., and Meijler, W.J. (2010). Spasticity: revisiting the role and the individual value of several pharmacological treatments. NeuroRehabilitation 27, 193-200.

283. Thomas, C.K., Hager-Ross, C.K., and Klein, C.S. (2010). Effects of baclofen on motor units paralysed by chronic cervical spinal cord injury. Brain 133, 117-125.

Address correspondence to:

Marie-Pascale Côté, PhD

Drexel University College of Medicine

Department of Neurobiology and Anatomy

Philadelphia, PA 19129

E-mail: marie-pascale.cote@drexelmed.edu 